Article

\title{
Enhanced Photocatalytic Activity toward Organic Pollutants Degradation and Mechanism Insight of Novel CQDs/ $\mathrm{Bi}_{2} \mathrm{O}_{2} \mathrm{CO}_{3}$ Composite
}

\author{
Zisheng Zhang ${ }^{1,2, *}$, Shuanglong Lin ${ }^{1}$, Xingang $\mathrm{Li}^{1,3}{ }^{3}$ Hong $\mathrm{Li}^{1}$, Tong Zhang ${ }^{4}$ \\ and Wenquan Cui ${ }^{4, *}$ (D) \\ 1 School of Chemical Engineering and Technology, Tianjin University, Tianjin 300072, China; \\ linshuanglong15@126.com (S.L.); lxg@tju.edu.cn (X.L.); lihong.tju@163.com (H.L.) \\ 2 Department of Chemical \& Biological Engineering, University of Ottawa, 161 Louis Pasteur St., \\ Ottawa, ON K1N6N5, Canada \\ 3 National Engineering Research Center of Distillation Technology, Tianjin 300072, China \\ 4 College of Chemical Engineering, North China University of Science and Technology, \\ Tangshan 063009, China; zhangt@126.com \\ * Correspondence: zzhang@uottawa.ca (Z.Z.); wkcui@163.com (W.C.); \\ Tel.: +001-613-796-9771 (Z.Z.); +86-315-2592169 (W.C.)
}

Received: 21 February 2018; Accepted: 10 May 2018; Published: 15 May 2018 updates

\begin{abstract}
Novel carbon quantum dots (CQDs) modified with $\mathrm{Bi}_{2} \mathrm{O}_{2} \mathrm{CO}_{3}\left(\mathrm{CQDs} / \mathrm{Bi}_{2} \mathrm{O}_{2} \mathrm{CO}_{3}\right)$ were prepared using a simple dynamic-adsorption precipitation method. X-ray diffractometry (XRD), transmission electron microscopy (TEM), energy dispersive X-ray spectroscopy (EDX), and scanning electron microscopy (SEM) were used to test the material composition, structure, and band structures of the as-prepared samples. Methylene blue (MB) and colorless phenol, as target organic pollutants, were used to evaluate the photocatalytic performance of the CQDs $/ \mathrm{Bi}_{2} \mathrm{O}_{2} \mathrm{CO}_{3}$ hybrid materials under visible light irradiation. Experimental investigation shows that 2-5 nm CQDs were uniformly decorated on the surface of $\mathrm{Bi}_{2} \mathrm{O}_{2} \mathrm{CO}_{3} ; \mathrm{CQDs} / \mathrm{Bi}_{2} \mathrm{O}_{2} \mathrm{CO}_{3}$ possess an efficient photocatalytic performance, and the organic matter removal rate of methylene blue and phenol can reach up to $94.45 \%$ and $61.46 \%$ respectively, within $2 \mathrm{~h}$. In addition, the degradation analysis of phenol by high performance liquid chromatography (HPLC) proved that there are no other impurities in the degradation process. Photoelectrochemical testing proved that the introduction of CQDs (electron acceptor) effectively suppresses the recombination of $\mathrm{e}^{-}-\mathrm{h}^{+}$, and promotes charge transfer. Quenching experiments and electron spin resonance (ESR) suggested that $\cdot \mathrm{OH}, \mathrm{h}^{+}$, and $\cdot \mathrm{O}_{2}{ }^{-}$were involved in the photocatalytic degradation process. These results suggested that the up-conversion function of CQDs could improve the electron transfer and light absorption ability of photocatalysts and $\cdot \mathrm{O}_{2}{ }^{-}$ formation. Furthermore, the up-conversion function of CQDs would help maintain photocatalytic stability. Finally, the photocatalytic degradation mechanism was proposed according to the above experimental result.
\end{abstract}

Keywords: $\mathrm{CQDs} / \mathrm{Bi}_{2} \mathrm{O}_{2} \mathrm{CO}_{3}$; up-conversion; flower microspheres; photocatalytic degradation

\section{Introduction}

In recent years, life and industrial sewage treatments have attracted increasing attention. Sewage is an important factor that affects environmental governance. Photocatalytic technology used for treating nocuous organic pollutants in water has recently received a lot of interest $[1,2]$. Pollutants can be effectively degraded via the generation of photoinduced electron-holes in photocatalysts under visible light irradiation. The above problems could be solved using semiconductor photocatalytic technology, 
which has been regarded as a promising green technology [3,4]. $\mathrm{TiO}_{2}$ has been a highly researched material because of its non-toxicity, chemical stability, commercial availability, high photoactivity, etc. [5-7] However, its practical application was limited by two main disadvantages: (1) poor visible light response ability, and (2) a low photogenerated charge separation efficiency [8]. Thus, many efforts have been made to explore new visible light photocatalytic materials which possess efficient photocatalytic activity.

In recent years, bismuth-based oxides which possess aurivillius-layered structures have been the focus of much research research, due to their hybridized valence band by $\mathrm{O}_{2 p}$ and $\mathrm{Bi}_{6 \mathrm{~s}}$ [9]. Some advantages of these photocatalysts are their good thermal stability, non-toxicity, etc. Some examples include $\mathrm{BiVO}_{4}$ [10-12], $\mathrm{BiWO}_{6}$ [13-15], $\mathrm{BiOX}(\mathrm{X}=\mathrm{Br}, \mathrm{Cl}, \mathrm{I})$ [16-18], $\mathrm{BiPO}_{4}$ [19], and $\mathrm{Bi}_{2} \mathrm{MoO}_{6}$ [20]. Among these photocatalysts, the $\mathrm{Bi}_{2} \mathrm{O}_{2} \mathrm{CO}_{3}$ photocatalyst is a new type of semiconductor photocatalytic material which has a unique layer structure consisting of $\mathrm{CO}_{3}{ }^{2-}$ layers interwoven by $\left[\mathrm{Bi}_{2} \mathrm{O}_{2}\right]^{2+}$ layers [21]. Thus, $\mathrm{Bi}_{2} \mathrm{O}_{2} \mathrm{CO}_{3}$ as a potential performance photocatalyst has gradually caught the attention of researchers. Thus far, the different morphological structures of $\mathrm{Bi}_{2} \mathrm{O}_{2} \mathrm{CO}_{3}$ have been studied, such as flower-like, sponge-like, porous ball, slice layer, etc. Various organic pollutants have also been used to investigate their photocatalytic performance [22,23]. However, because of its weak visible light response and wide band structure, modification research of $\mathrm{Bi}_{2} \mathrm{O}_{2} \mathrm{CO}_{3}$ is very important [24]. Hence, an effective way to improve the photocatalytic performance of $\mathrm{Bi}_{2} \mathrm{O}_{2} \mathrm{CO}_{3}$ may be to introduce a narrow band gap semiconductor, such as $\mathrm{Bi}_{2} \mathrm{O}_{2} \mathrm{CO}_{3} / \mathrm{BiOI}$ [25], $\mathrm{Ag}-\mathrm{AgBr} / \mathrm{Bi}_{2} \mathrm{O}_{2} \mathrm{CO}_{3}$ [26], $\mathrm{Bi}_{2} \mathrm{O}_{2} \mathrm{CO}_{3} / \mathrm{Bi}_{2} \mathrm{~S}_{3}$ [27], etc.

Carbon quantum dots (CQDs), which are smaller than $10 \mathrm{~nm}$ in size, are well-dispersed spherical fluorescent nanocarbon materials. They gradually roused interest because of their easy functionalization, powerful chemical inertness, good photo-stability, excellent biocompatibility, and non-toxicity [28-30]. In addition, its photoluminescence (PL) up-conversion is a unique property [31]. Visible light emissions and shorter wavelength UV could be generated from near infrared (NIR) light radiation. The long wavelength of visible light makes CQDs a potential material for photocatalysis, solar cells, bioluminescence, etc., via the PL up-conversion effect [32-34].

CQDs can be either photoinduced electron donors or acceptors, due to their photoelectrochemical properties and their being richly fluorescent [28,35]. CQDs can either be used as a photocatalytic material or as functional components in composite photocatalyst designs to broaden the spectrum response range and promote the separation of photoinduced $\mathrm{e}^{-}-\mathrm{h}^{+}$[32]. They can also inhibit semiconductor photolysis, such as in $\mathrm{CQDs} / \mathrm{Fe}_{2} \mathrm{O}_{3}$ [36] and CQDs/ $\mathrm{ZnO}$ [37].

In this research, we present a simple method to fabricate CQDs $/ \mathrm{Bi}_{2} \mathrm{O}_{2} \mathrm{CO}_{3}$ composite with 3D flower micro-sphered structures. Structure and morphology characterizations, as well as the mechanism behind the efficiency promotion effect of $\mathrm{CQDs} / \mathrm{Bi}_{2} \mathrm{O}_{2} \mathrm{CO}_{3}$, were carefully studied. The photocatalytic property of the CQDs $/ \mathrm{Bi}_{2} \mathrm{O}_{2} \mathrm{CO}_{3}$ compound was investigated by removing methylene blue (MB) and colorless phenol, under simulated sunlight irradiation.

\section{Experimental Methods}

\subsection{Photocatalyst Synthesis}

All of the chemicals are analytical reagents without further purification.

\subsubsection{Synthesis of the 3D Flower-Like $\mathrm{Bi}_{2} \mathrm{O}_{2} \mathrm{CO}_{3}$}

The 3D flower-like $\mathrm{Bi}_{2} \mathrm{O}_{2} \mathrm{CO}_{3}$ precursor was prepared by using the classic hydrothermal method. Using a classic course to synthesize the $\mathrm{Bi}_{2} \mathrm{O}_{2} \mathrm{CO}_{3}$ flower-like precursor, $0.003 \mathrm{~mol}$ of $\mathrm{Bi}\left(\mathrm{NO}_{3}\right)_{3} \cdot 5 \mathrm{H}_{2} \mathrm{O}$ was dissolved in $20 \mathrm{~mL}$ of $1 \mathrm{M} \mathrm{HNO}_{3}$, and then $0.002 \mathrm{~mol}$ of citric acid was added. After $10 \mathrm{~min}$ stirring, $\mathrm{NaOH}$ was added to adjust the $\mathrm{pH}$ of the above reaction solution to 4.0-4.2. Then the reaction solution was transferred in a Teflon-lined, stainless steel autoclave, and maintained at $160{ }^{\circ} \mathrm{C}$ for $24 \mathrm{~h}$. 
After natural cooling to room temperature, the prepared precursor was handled by repeated washing and centrifugation with ethanol and distilled water, and subsequently dried at $80{ }^{\circ} \mathrm{C}$ for $8 \mathrm{~h}$.

\subsubsection{Preparation of Carbon Quantum Dots (CQDs)}

A pair of graphite rods with a $7.5 \mathrm{~cm}$ separation were parallelly inserted into deionized water as the anode and counter-electrode $\left(18.4 \mathrm{M} \Omega \cdot \mathrm{cm}^{-1}, 400 \mathrm{~mL}\right)$ [38]. A direct current (DC) supplies a $30 \mathrm{~V}$ static potential to the two electrodes. The solution then gradually became dark yellow, with corrosion being observed on the anode graphite rod. Finally, solution became a dark brown after a period of electrolytic process. The electrolyte was first filtered with filter paper. The filtrate was then centrifuged at 22,000 rpm for $30 \mathrm{~min}$, which could remove the graphite particles and graphite oxide. The resultant solution is the ideal CQDs aqueous solution. $\left(\mathrm{C}_{(\mathrm{CQDs})}=2.01 \mathrm{~g} / \mathrm{L}\right)$

\subsubsection{Preparation of $\mathrm{CQD} / \mathrm{Bi}_{2} \mathrm{O}_{2} \mathrm{CO}_{3}$ Photocatalysts}

$\mathrm{CQD} / \mathrm{Bi}_{2} \mathrm{O}_{2} \mathrm{CO}_{3}$ composites were synthesized by a simple dynamic adsorption precipitation method. $0.3 \mathrm{~g}$ of $\mathrm{Bi}_{2} \mathrm{O}_{2} \mathrm{CO}_{3}$ photocatalyst were added to $50 \mathrm{~mL}$ of deionized water under ultrasonic treatment for $1 \mathrm{~h}$. Next, a defined volume of CQD solution (10, 30, 50, 70 and $90 \mathrm{~mL})$ was added to the above solution and stirred for $90 \mathrm{~min}$ at room temperature to create a clear dispersion of CQDs. The obtained samples were labeled as 10-CQDs $/ \mathrm{Bi}_{2} \mathrm{O}_{2} \mathrm{CO}_{3}, 30-\mathrm{CQDs} / \mathrm{Bi}_{2} \mathrm{O}_{2} \mathrm{CO}_{3}, 50-\mathrm{CQDs} / \mathrm{Bi}_{2} \mathrm{O}_{2} \mathrm{CO}_{3}$, 70-CQDs $/ \mathrm{Bi}_{2} \mathrm{O}_{2} \mathrm{CO}_{3}, 90-\mathrm{CQDs} / \mathrm{Bi}_{2} \mathrm{O}_{2} \mathrm{CO}_{3}$, respectively. The CQD/ $\mathrm{Bi}_{2} \mathrm{O}_{2} \mathrm{CO}_{3}$ photocatalysts were handled by repeated washing and centrifugation with ethanol and distilled water, and subsequently dried at $80{ }^{\circ} \mathrm{C}$ for $8 \mathrm{~h}$.

\subsection{Photocatalyst Characterization}

The crystal structures and phase data of samples could be determined by X-ray diffractometry (XRD) (D/MAX2500 PC, Rigaku Corporation, Tokyo, Japan). The morphologies and composition of the samples could be investigated by transmission electron microscopy (TEM) (JEM-2010, JEOL Ltd., Akishima, Japan), energy dispersive X-ray spectroscopy (EDX) (s-4800, Hitachi, Chiyoda, Japan), and scanning electron microscopy (SEM) (s-4800, Hitachi, Chiyoda, Japan). The spectrofluorometer (f7000, Hitachi, Chiyoda, Japan) could be used to investigate the separation efficiency of photo-induced charge for powdered samples. The Perkin Elmer System 2000 infrared spectrometer provided the Fourier transform infrared (FTIR) spectra (Perkin Elmer, Shanghai, China), with $\mathrm{KBr}$ as the reference sample. The spin trapping electron spin resonance (ESR) measurements were performed on a Bruker JES FA200 ESR spectrometer (Oubeier, Beijing, China). The electrochemical and photoelectrochemical measurements were performed via a three-electrode quartz cell system. A CHI 660B electrochemical system (Shanghai Chenhua Instrument Corp., Shanghai, China) was used to record the photoelectrochemical results.

\subsection{Photocatalytic Activity}

The degradation rate of $\mathrm{MB}$ (or colorless phenol) was used to test the photocatalytic performance of $\mathrm{CQDs} / \mathrm{Bi}_{2} \mathrm{O}_{2} \mathrm{CO}_{3}$ samples under the simulated sunlight (a $400 \mathrm{~W}$ metal halide lamp, $\lambda>400 \mathrm{~nm}$, transmittance $>90 \%$ ) in a multi-tube agitated reactor (XPA-7) (Xujiang, Nanjing, China). Thermostatic water provided cooling to control the reaction temperature $\left(25 \pm 2{ }^{\circ} \mathrm{C}\right)$. Firstly, $0.05 \mathrm{~g}$ of $\mathrm{CQDs} / \mathrm{Bi}_{2} \mathrm{O}_{2} \mathrm{CO}_{3}$ powder was added to $50 \mathrm{~mL}$ of a $10 \mathrm{mg} / \mathrm{L} \mathrm{MB}$ solution. Before light source irradiation, it was necessary to reach adsorption equilibrium for CQDs $/ \mathrm{Bi}_{2} \mathrm{O}_{2} \mathrm{CO}_{3}$ in the absence of light about $30 \mathrm{~min}$. During metal halide lamp irradiation, $3 \mathrm{~mL}$ reaction solution was measured out every $15 \mathrm{~min}$ in $120 \mathrm{~min}$ and stored in a dark environment. Finally, the collected reaction solutions were centrifuged for $6 \mathrm{~min}$ at 10,000 rpm, to separate the sample particles. A UV-vis spectrophotometer (UV-1901, Puxi, Beijing, China) was used to analyze the supernatant solutions (MB). (The determining wavelength: $400 \mathrm{~nm}<\lambda<800 \mathrm{~nm}$ ) 
The degradation efficiency (\%) was calculated as follows:

$$
\text { Degradation }(\%)=\frac{C_{0}-C}{C_{0}} \times 100 \%
$$

where $C$ and $C_{0}$ were the $t$ min and initial concentration of $\mathrm{MB}$, respectively.

Additionally, blank and contrast tests were also performed. However, the high-performance liquid chromatography (HPLC) was used to analyze the concentration of phenol. The HPLC column was a $15 \mathrm{~cm} \times 4.6 \mathrm{~mm} \mathrm{C18}$ column with a particle size of $5 \mu \mathrm{m}$. The mobile phase consisted of methanol/water $=70: 30$. The flow rate was $1 \mathrm{~mL} / \mathrm{min}$ and column temperature of $35^{\circ} \mathrm{C}$.

\subsection{Photoelectrocatalytic Activity}

A photoelectrocatalytic test was used to evaluate the charge separation efficiency of the $\mathrm{CQDs} / \mathrm{Bi}_{2} \mathrm{O}_{2} \mathrm{CO}_{3}$. In the test, $\mathrm{CHI} 660 \mathrm{E}$ Electrochemical Workstation (Shanghai Chenhua Instrument Corp., Shanghai, China) carried out all photoelectrochemical experiments results via a conventional three-electrode quartz cell system in a homemade quartz reactor (electrolyte: $0.1 \mathrm{M} \mathrm{Na}_{2} \mathrm{SO}_{4}$ ). A 500-W Xe lamp purchased (Beijing Changtuo Co. Ltd., Beijing, China) with a UV cut-off filter $(420 \mathrm{~nm})$ was used for light source. The prepared photoelectrode was used as a working electrode, while $\mathrm{Pt}$ was used as a counter electrode, and a saturated calomel electrode (SCE) was used as the reference electrode.

\section{Results and Discussion}

\subsection{Catalyst Characterization}

Figure 1 shows the XRD characteristic peak of the $\mathrm{Bi}_{2} \mathrm{O}_{2} \mathrm{CO}_{3}$ and different $\mathrm{CQDs} / \mathrm{Bi}_{2} \mathrm{O}_{2} \mathrm{CO}_{3}$ composites, with various modified quantities of CQDs. The composition and crystalline properties of the photocatalysts can be identified using XRD. As shown, the curve of pure $\mathrm{Bi}_{2} \mathrm{O}_{2} \mathrm{CO}_{3}$ possesses many characteristic and distinct diffraction peaks, which perfectly match the diffraction peaks of tetragonal phase $\mathrm{Bi}_{2} \mathrm{O}_{2} \mathrm{CO}_{3}$ (JCPDS: 41-1488), suggesting satisfactory composition and purity. The main characteristic peak positions of samples appeared at $12.93^{\circ}, 23.90^{\circ}, 26.03^{\circ}, 30.25^{\circ}, 32.73^{\circ}, 35.31^{\circ}, 39.51^{\circ}$, $42.30^{\circ}, 46.97^{\circ}, 48.93^{\circ}, 52.23^{\circ}, 53.41^{\circ}, 54.51^{\circ}$ and $56.90^{\circ}$. This corresponds to the (002), (011), (004), (013), (110), (112), (006), (114), (020), (022), (116), (121), (024) and (123) crystal faces of $\mathrm{Bi}_{2} \mathrm{O}_{2} \mathrm{CO}_{3}$, respectively. In addition, the sharp and intense characteristic peaks suggested that the samples possessed good crystallinity. The XRD patterns of $\mathrm{CQDs} / \mathrm{Bi}_{2} \mathrm{O}_{2} \mathrm{CO}_{3}$ photocatalysts were largely similar to those of $\mathrm{Bi}_{2} \mathrm{O}_{2} \mathrm{CO}_{3}$. The diffraction peaks of CQDs were not obvious, even at highly modified amounts, due to high dispersion and the small amount of the CQDs in the $C Q D s / \mathrm{Bi}_{2} \mathrm{O}_{2} \mathrm{CO}_{3}$ composite.

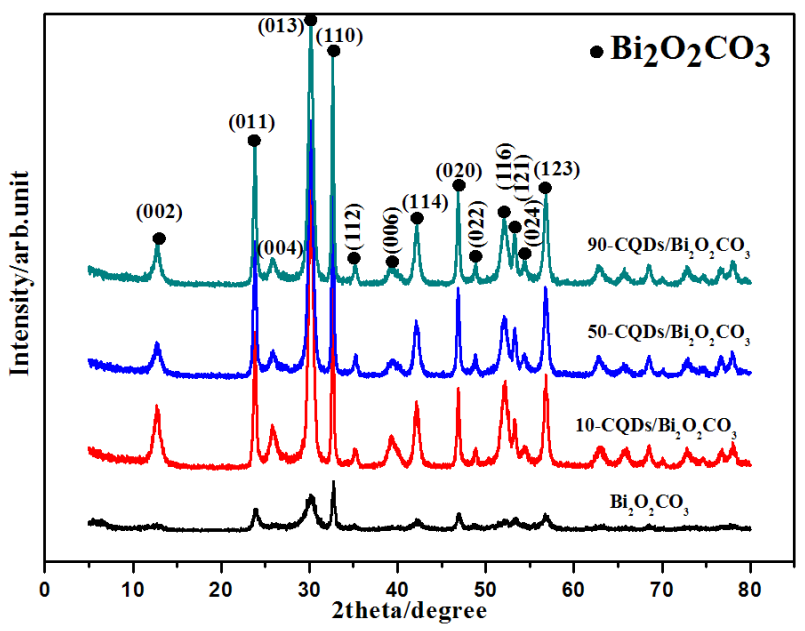

Figure 1. XRD patterns of the synthesized photocatalysts. 
An ultraviolet-visible (UV-vis) diffuse reflection spectrum can be used to measure the light absorption ability of photocatalysts. Additionally, the band gap energies of semiconductor photocatalysts could be calculated according to their electronic structure features on the UV-vis absorption curve. As shown in Figure S1a, less than $370 \mathrm{~nm}$ of UV light can be absorbed by the pure $\mathrm{Bi}_{2} \mathrm{O}_{2} \mathrm{CO}_{3}$ sample. The absorption ability of $\mathrm{Bi}_{2} \mathrm{O}_{2} \mathrm{CO}_{3}$ was weak in the visible region. After the introduction of CQDs, the light absorption ability of $\mathrm{Bi}_{2} \mathrm{O}_{2} \mathrm{CO}_{3}$ was markedly enhanced, and the absorption edges of the CQDs $/ \mathrm{Bi}_{2} \mathrm{O}_{2} \mathrm{CO}_{3}$ exhibited a slight systematic red-shift. Furthermore, the light absorption intensity of CQDs $/ \mathrm{Bi}_{2} \mathrm{O}_{2} \mathrm{CO}_{3}$ composites were obviously enhanced with increases of the CQD content. Additionally, the absorption spectrum of CQDs further confirms that the up-conversion function of CQDs could promote full spectrum absorption. Figure S1b shows the band gap energies of the prepared photocatalysts. The forbidden band of a crystalline semiconductor could be calculated using the following formula [39]:

$$
\alpha \mathrm{h} v=\mathrm{A}\left(\mathrm{h} v-E_{g}\right)^{n / 2}
$$

where $\alpha$ is the absorption coefficient, $h$ is the Plank constant, $v$ is the light frequency, $E_{g}$ is the band gap and $\mathrm{A}$ is a constant [40].

The value of $n$ is 1 or 4 , depending on the photocatalyst type for a direct or indirect transition, respectively. Therefore, the $n$ value of $\mathrm{Bi}_{2} \mathrm{O}_{2} \mathrm{CO}_{3}$ is 4 due to the indirect transition band gaps [41,42]. The plot of $(\alpha \mathrm{h} v)^{1 / 2}$ versus the photon energy $(\mathrm{h} v)$ could calculated the band gap energy of $\mathrm{Bi}_{2} \mathrm{O}_{2} \mathrm{CO}_{3}$ and CQDs $/ \mathrm{Bi}_{2} \mathrm{O}_{2} \mathrm{CO}_{3}$ through the intercept of the tangent to the $x$-axis. As shown in Figure $\mathrm{S} 1 \mathrm{~b}$, the band gap of pure $\mathrm{Bi}_{2} \mathrm{O}_{2} \mathrm{CO}_{3}$ was approximately $3.4 \mathrm{eV}$. The above results indicated that CQDs $/ \mathrm{Bi}_{2} \mathrm{O}_{2} \mathrm{CO}_{3}$ composites have significant visible light absorption ability, due to the deposition and up-conversion behavior of CQDs. The introduction of CQDs effectively promotes the charge-transfer between CQDs and $\mathrm{Bi}_{2} \mathrm{O}_{2} \mathrm{CO}_{3}$. It broadens the optical absorption edges and enhanced the optical absorption intensity of $\mathrm{CQDs} / \mathrm{Bi}_{2} \mathrm{O}_{2} \mathrm{CO}_{3}$ composites. In summary, the up-conversion behavior of CQDs effectively improved the photocatalytic degradation ability of $\mathrm{CQDs} / \mathrm{Bi}_{2} \mathrm{O}_{2} \mathrm{CO}_{3}$ photocatalysts under visible light irradiation.

Valence band X-ray photoelectron spectroscopy (VB XPS) could be used to calculate the valence band (VB) position of photocatalysts. As shown in Figure S2a, the valence band of $\mathrm{Bi}_{2} \mathrm{O}_{2} \mathrm{CO}_{3}$ is about $3.56 \mathrm{eV}$. According to the result of Figure S1b, the conduction band (CB) edge of $\mathrm{Bi}_{2} \mathrm{O}_{2} \mathrm{CO}_{3}$ should be located at $0.16 \mathrm{eV}$. This result is supported by the Mott-Schottky (MS) plots experiment (Figure S2b). The MS plots for $\mathrm{Bi}_{2} \mathrm{O}_{2} \mathrm{CO}_{3}$ indicate typical n-type semiconductors with a typical shape [43]. The conduction band is about $0.15 \mathrm{eV}$. The measured value was close to the calculated value. The above results could provide a strong theoretical basis for the discussion of the photocatalytic degradation mechanism.

The TEM analysis was used to characterize the microstructure and morphology of $\mathrm{Bi}_{2} \mathrm{O}_{2} \mathrm{CO}_{3}$ and $\mathrm{CQDs} / \mathrm{Bi}_{2} \mathrm{O}_{2} \mathrm{CO}_{3}$. Figure 2a shows the TEM image of the prepared $\mathrm{Bi}_{2} \mathrm{O}_{2} \mathrm{CO}_{3}$ sample. The average diameter of the flower-like microsphere structure was about 1 to $2 \mu \mathrm{m}$, which consists of 2D nanosheet structures. Figure $2 b, c$ show the TEM images of CQDs $/ \mathrm{Bi}_{2} \mathrm{O}_{2} \mathrm{CO}_{3}$ samples. It is obvious that a mass of CQDs are evenly attached to the surface of the $\mathrm{Bi}_{2} \mathrm{O}_{2} \mathrm{CO}_{3}$ "flower-like" nanosheets. The results demonstrated that the CQDs modified on the surface of $\mathrm{Bi}_{2} \mathrm{O}_{2} \mathrm{CO}_{3}$ were homodisperse, with a 2-5 nm spherical diameter. The modifications of CQDs can significantly increase the number of photocatalytic reaction sites and the surface roughness of the $\mathrm{Bi}_{2} \mathrm{O}_{2} \mathrm{CO}_{3}$ flower structure [44], thereby significantly improving the photocatalytic degradation efficiency. The HRTEM image (Figure 2d) showed that the interplanar spacing of CQDs and $\mathrm{Bi}_{2} \mathrm{O}_{2} \mathrm{CO}_{3}$ was 0.33 and $0.30 \mathrm{~nm}$, corresponding to the (002) and (013) crystallographic planes, respectively. Figure 2e shows the selected-area electron diffraction (SAED) pattern of CQDs $/ \mathrm{Bi}_{2} \mathrm{O}_{2} \mathrm{CO}_{3}$. The high-crystallinity of $\mathrm{CQDs} / \mathrm{Bi}_{2} \mathrm{O}_{2} \mathrm{CO}_{3}$ photocatalysts was obvious according to the clear lattice fringe. The elemental composition of the CQDs $/ \mathrm{Bi}_{2} \mathrm{O}_{2} \mathrm{CO}_{3}$ photocatalyst was estimated using EDS analysis. The EDS spectrum shown in Figure $2 \mathrm{f}$ revealed that the $\mathrm{CQDs} / \mathrm{Bi}_{2} \mathrm{O}_{2} \mathrm{CO}_{3}$ composite photocatalyst contained only $\mathrm{Bi}, \mathrm{C}$, and $\mathrm{O}$. The measured value of the $\mathrm{C}$ element was more than predicted in the theoretical value of $\mathrm{C}$ in $\mathrm{Bi}_{2} \mathrm{O}_{2} \mathrm{CO}_{3}$, which confirmed the 
existence of CQDs on the surface of $\mathrm{Bi}_{2} \mathrm{O}_{2} \mathrm{CO}_{3}$. The above results indicate the effective compounding of CQDs and $\mathrm{Bi}_{2} \mathrm{O}_{2} \mathrm{CO}_{3}$.

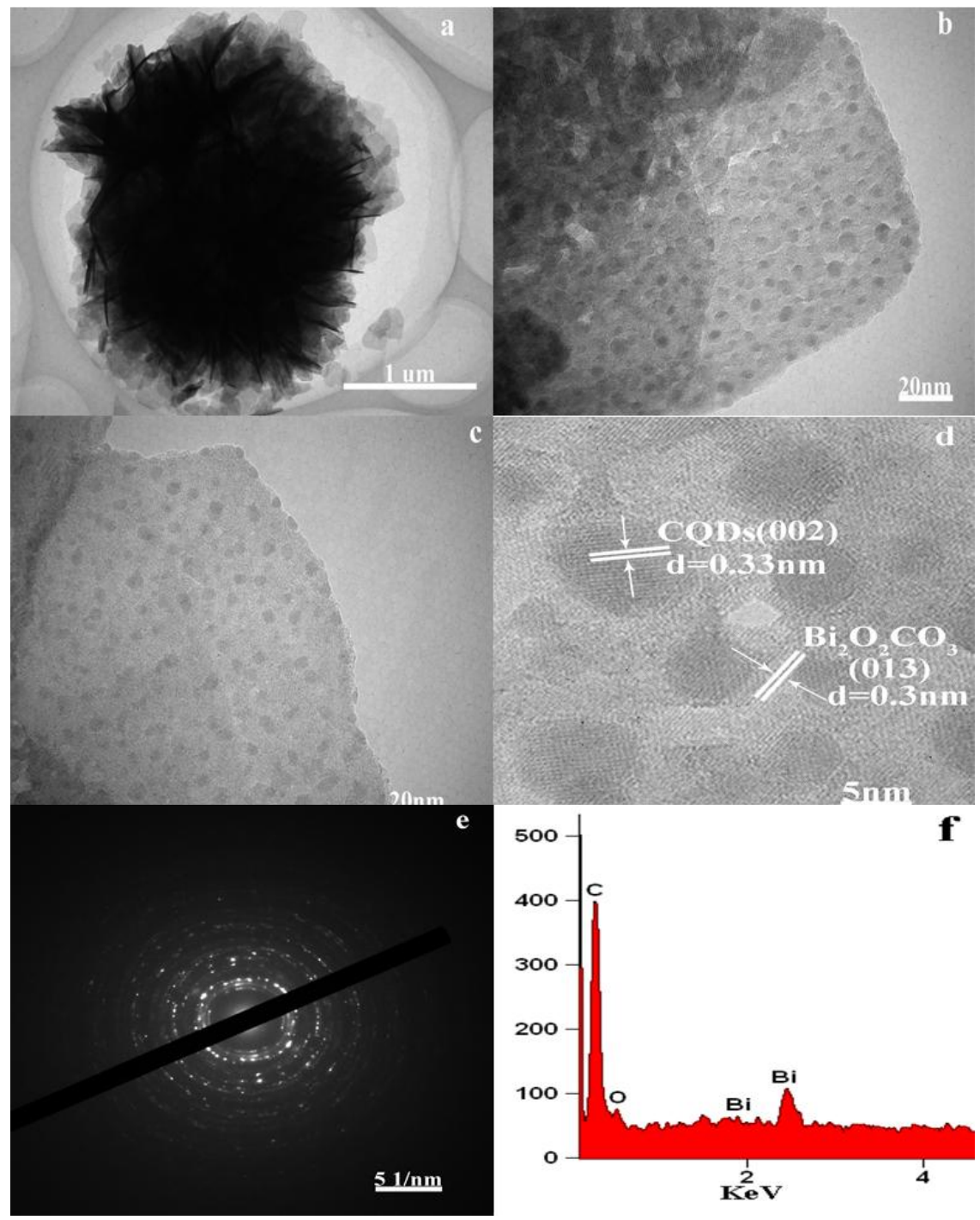

Figure 2. TEM images of as-prepared samples: (a) $\mathrm{Bi}_{2} \mathrm{O}_{2} \mathrm{CO}_{3} ;(\mathbf{b}, \mathbf{c})$ CQDs $/ \mathrm{Bi}_{2} \mathrm{O}_{2} \mathrm{CO}_{3} ;(\mathbf{d}-\mathbf{f}) \mathrm{HRTEM}$, SAED, EDX images of CQDs $/ \mathrm{Bi}_{2} \mathrm{O}_{2} \mathrm{CO}_{3}$.

Figure 3a shows the photoluminescence (PL) spectra of $\mathrm{Bi}_{2} \mathrm{O}_{2} \mathrm{CO}_{3}$ and $\mathrm{CQDs} / \mathrm{Bi}_{2} \mathrm{O}_{2} \mathrm{CO}_{3}$. The PL spectra were dependent on the $260 \mathrm{~nm}$ excitation wavelengths. It is known that the recombination degree of the photogenerated $\mathrm{e}^{-}-\mathrm{h}^{+}$could be reflected by the PL technique. Therefore, to a certain extent, the PL spectra could reflect the photocatalytic properties of semiconductors. Clearly, the shapes and peak positions of $\mathrm{Bi}_{2} \mathrm{O}_{2} \mathrm{CO}_{3}$ were similar to those of $\mathrm{CQDs} / \mathrm{Bi}_{2} \mathrm{O}_{2} \mathrm{CO}_{3}$. However, the peak intensity of $\mathrm{CQDs} / \mathrm{Bi}_{2} \mathrm{O}_{2} \mathrm{CO}_{3}$ decreased, suggesting the high separation efficiency of the carrier charge when CQDs are decorated on the surface of $\mathrm{Bi}_{2} \mathrm{O}_{2} \mathrm{CO}_{3}$. Figure $3 \mathrm{~b}$ shows the fluorescence spectrum peaks of CQDs excited by long wavelengths. The up-conversion PL spectra show excitation-dependent PL feature spectra. With the excitation wavelengths increasing from $600 \mathrm{~nm}$ to $900 \mathrm{~nm}$, the up-converted emission peaks exhibit a red shift from $430 \mathrm{~nm}$ to $520 \mathrm{~nm}$. The above results show that CQDs have strong fluorescence up-conversion properties. 

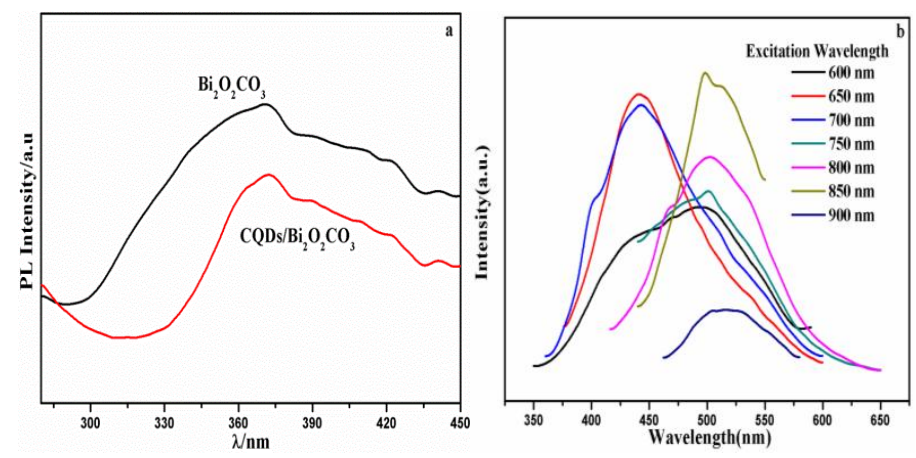

Figure 3. (a) Photoluminescence (PL) spectra of $\mathrm{Bi}_{2} \mathrm{O}_{2} \mathrm{CO}_{3}$ and $\mathrm{CQDs} / \mathrm{Bi}_{2} \mathrm{O}_{2} \mathrm{CO}_{3}$; (b) PL curve of CQDs excited by different wavelengths of light.

The presence of CQDs in CQDs $/ \mathrm{Bi}_{2} \mathrm{O}_{2} \mathrm{CO}_{3}$ photocatalysts could be further determined using a Fourier transform of the infrared (FTIR) spectra. As shown in Figure S3, by comparing the FTIR spectrums of $\mathrm{CQDs}, \mathrm{Bi}_{2} \mathrm{O}_{2} \mathrm{CO}_{3}$ and $\mathrm{CQDs} / \mathrm{Bi}_{2} \mathrm{O}_{2} \mathrm{CO}_{3}$, no obvious impurity absorption peaks were detected. For the $\mathrm{CQDs} / \mathrm{Bi}_{2} \mathrm{O}_{2} \mathrm{CO}_{3}$ material, the stretching vibrations of the $\mathrm{Bi}-\mathrm{O}$ in $\mathrm{Bi}_{2} \mathrm{O}_{2} \mathrm{CO}_{3}$ could be obtained according to the intensive peaks at about $560-850 \mathrm{~cm}^{-1}$. The stretching vibrations of $\mathrm{C}-\mathrm{O}$ and $\mathrm{C}=\mathrm{O}$ were assigned to the peaks at approximately $1400 \mathrm{~cm}^{-1}$ [45], respectively. The absorption band at approximately $1040 \mathrm{~cm}^{-1}$ attributes to $\mathrm{C}-\mathrm{C}$ or $\mathrm{C}-\mathrm{O}$ stretching vibrations. The existence of $\mathrm{COO}^{-}$in CQDs could be proven by the presence of $1452 \mathrm{~cm}^{-1}$ absorption peaks [46]. The peaks at $1705-3454 \mathrm{~cm}^{-1}$ are due to the bending vibrations of water molecules absorbed on CQDs $/ \mathrm{Bi}_{2} \mathrm{O}_{2} \mathrm{CO}_{3}$, and stretching vibrations of the $-\mathrm{OH}$ group. The peaks at about $2950 \mathrm{~cm}^{-1}$ are attributed to $\mathrm{C}-\mathrm{H}$ stretching and rocking band vibrations, respectively [47]. All these results successfully prove the existence of $\mathrm{CQDs}$ and $\mathrm{Bi}_{2} \mathrm{O}_{2} \mathrm{CO}_{3}$, and suggest the combination and an interface interaction between CQDs and $\mathrm{Bi}_{2} \mathrm{O}_{2} \mathrm{CO}_{3}$. The XPS analysis (Figure 4) could be further used to prove the results.
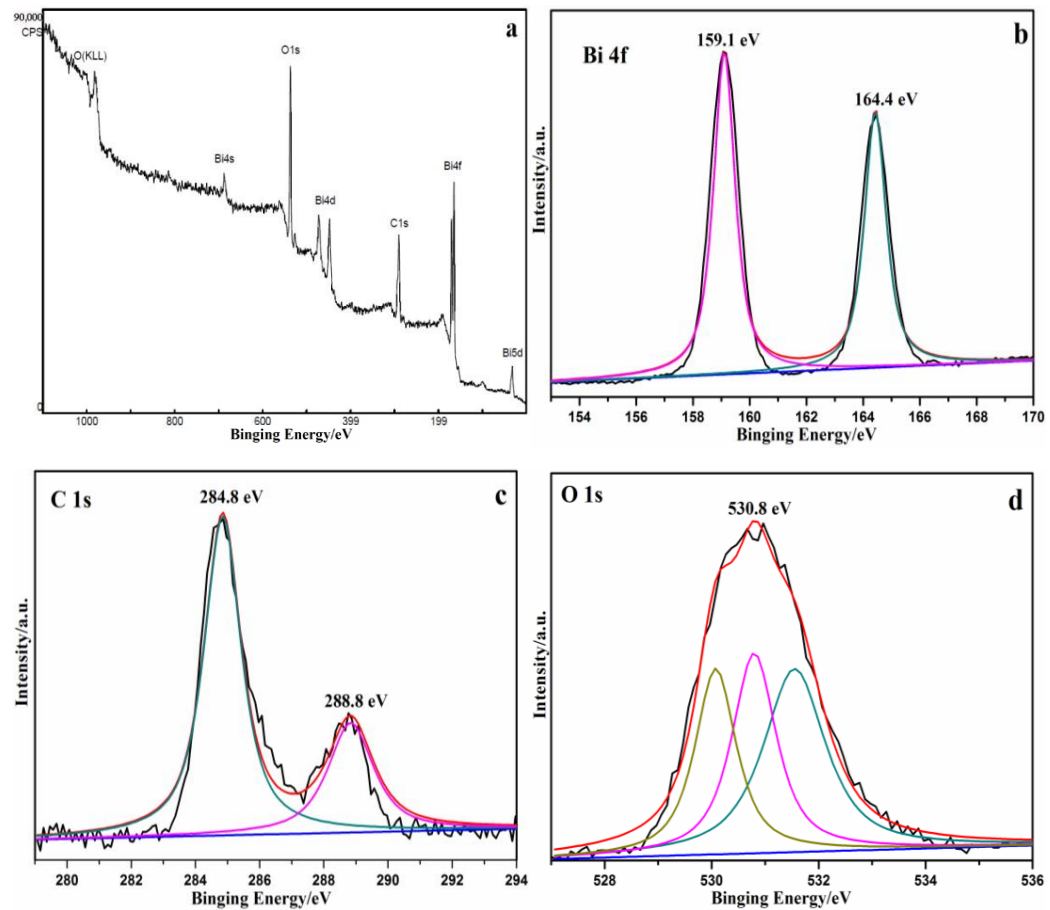

Figure 4. XPS characteristic peak of the $\mathrm{CQDs} / \mathrm{Bi}_{2} \mathrm{O}_{2} \mathrm{CO}_{3}$ sample. (a) Survey of the sample; (b) $\mathrm{Bi} 4 \mathrm{f}$; (c) $\mathrm{C} 1 \mathrm{~s} ;$ (d) O $1 \mathrm{~s}$. 
The surface properties and chemical compositions of the samples could be determined by using an X-ray photoelectron spectrometer (XPS). Figure 4a displays the full survey spectrum of CQDs $/ \mathrm{Bi}_{2} \mathrm{O}_{2} \mathrm{CO}_{3}$, which suggested the existence of oxygen (O 1s), carbon (C 1s) and bismuth (Bi 4f).

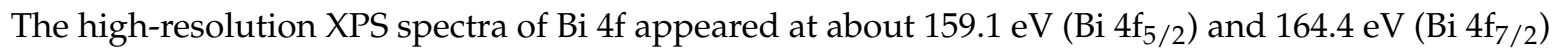
(Figure $4 \mathrm{~b}$ ), which belong to a crystal structure of $\mathrm{Bi}^{3+}$ [48]. In the narrow scan of the $\mathrm{C} 1 \mathrm{~s}$ (Figure $4 \mathrm{c}$ ), the main peak at $284.8 \mathrm{eV}$ is ascribed to the $\mathrm{C}-\mathrm{C}$ sp2-hybridizedcarbon of CQDs [49]. The characteristic peaks of the $\mathrm{C} 1 \mathrm{~s}$, which appeared at $288.8 \mathrm{eV}$, was due to the presence of $\mathrm{C}-\mathrm{O}-\mathrm{C}$ and / or $\mathrm{C}=\mathrm{O}$ [50]. The peak of $\mathrm{O} 1 \mathrm{~s}$ was shown in Figure $4 \mathrm{~d}$. The characteristic peak could be split into three peaks. The peaks at 531.5, 530.8 and $530.0 \mathrm{eV}$ are ascribed to adsorption oxygen, hydroxyl oxygen, and lattice oxygen, respectively. The presence of CQDs in CQDs $/ \mathrm{Bi}_{2} \mathrm{O}_{2} \mathrm{CO}_{3}$ samples could be confirmed according to the $\mathrm{C} 1 \mathrm{~s}$ and $\mathrm{O} 1$ s patterns, which are consistent with the FTIR analysis results (Figure S4).

\subsection{Photocatalytic Activity}

MB was used as target pollutants to evaluate the photocatalytic degradation performance of the prepared samples under metal halide lamp irradiation. The $30 \mathrm{~min}$ absorption process was used to ensure the absorption-desorption balance between the photocatalyst and pollutants. Firstly, the degradation of MB by the composite without light irradiation, as well as the direct photolysis of $\mathrm{MB}$ without a photocatalyst, was investigated; the results are presented in Figure $5 \mathrm{a}$. In the dark or without a photocatalyst, only a slight degradation of MB was observed. However, it is obvious that the photocatalytic property of $\mathrm{Bi}_{2} \mathrm{O}_{2} \mathrm{CO}_{3}$ improved significantly with the introduction of CQDs. 50-CQDs $/ \mathrm{Bi}_{2} \mathrm{O}_{2} \mathrm{CO}_{3}$ showed the highest degradation efficiency $(94.45 \%)$ within a $2 \mathrm{~h}$ irradiation, which was higher than that of $\mathrm{Bi}_{2} \mathrm{O}_{2} \mathrm{CO}_{3}(54.43 \%)$ for the same time period. CQDs could promote the photocatalytic process by improving the visible light responsiveness, or enhancing the charge separation efficiency of the system. Specifically, $\mathrm{Bi}_{2} \mathrm{O}_{2} \mathrm{CO}_{3}$ could be excited to generate the electrons-hole pairs by short wavelengths (ultraviolet light) by up-converting the long wavelength (visible light) via CQDs on the surface of $\mathrm{Bi}_{2} \mathrm{O}_{2} \mathrm{CO}_{3}$. Meanwhile, CQDs function as an excellent electron mediator and acceptor in $\mathrm{CQDs} / \mathrm{Bi}_{2} \mathrm{O}_{2} \mathrm{CO}_{3}$ to effectively separate $\mathrm{e}^{-}-\mathrm{h}^{+}$pairs, and improve degradation efficiency. The function mechanism was similar to that of previous studies [51-53]. Figure $5 \mathrm{~b}$ shows the UV-vis absorption spectra temporal changes for MB solutions in the presence of $50-\mathrm{CQDs} / \mathrm{Bi}_{2} \mathrm{O}_{2} \mathrm{CO}_{3}$. It is obvious that the arresting characteristic peak $(664 \mathrm{~nm})$ weakened in intensity as the reaction time increased. Therefore, the final solution almost became colorless from the initial blue after approximately $120 \mathrm{~min}$ of irradiation, which further implies the complete destruction of the conjugated structure of $\mathrm{MB}$. Figure $5 \mathrm{c}$ shows the total organic carbon (TOC) removal of $\mathrm{MB}$ as a function of reaction time. After 120 min illumination, the TOC removal by $\mathrm{Bi}_{2} \mathrm{O}_{2} \mathrm{CO}_{3}$ and 50-CQDs $/ \mathrm{Bi}_{2} \mathrm{O}_{2} \mathrm{CO}_{3}$ were $4.67 \%$ and $80.64 \%$, respectively. Additionally, High performance liquid chromatography (HPLC) was used to further verify the degradation process.

As is known, pseudo-first-order kinetics is suitable for the photocatalytic degradation of organic pollutants. The $k_{\text {app }}$ values of $\mathrm{CQDs} / \mathrm{Bi}_{2} \mathrm{O}_{2} \mathrm{CO}_{3}$ composites with different amounts of CQDs are shown in Figure S4. More CQDs resulted in higher kinetic constants for the CQDs $/ \mathrm{Bi}_{2} \mathrm{O}_{2} \mathrm{CO}_{3}$, and the highest kinetic constant $\left(0.0214 \mathrm{~min}^{-1}\right)$ appeared when using $50 \mathrm{~mL}$ of CQDs. The kinetic constant did not increase with a further increase of CQDs, and even decreased sharply when $90 \mathrm{~mL}$ of CQDs was used. This may be due to the fact that when the CQD content is sufficiently high, there is an associated decrease in the number of available active sites, and thus, lower photoelectrocatalytic activity [54]. In such a situation, excess CQDs could act as recombination sites for electron-hole pairs. A suitable quantity of CQDs could effectively improve the synergetic effects of CQDs and $\mathrm{Bi}_{2} \mathrm{O}_{2} \mathrm{CO}_{3}$, which largely contributes to the separation of electron-hole pairs. 

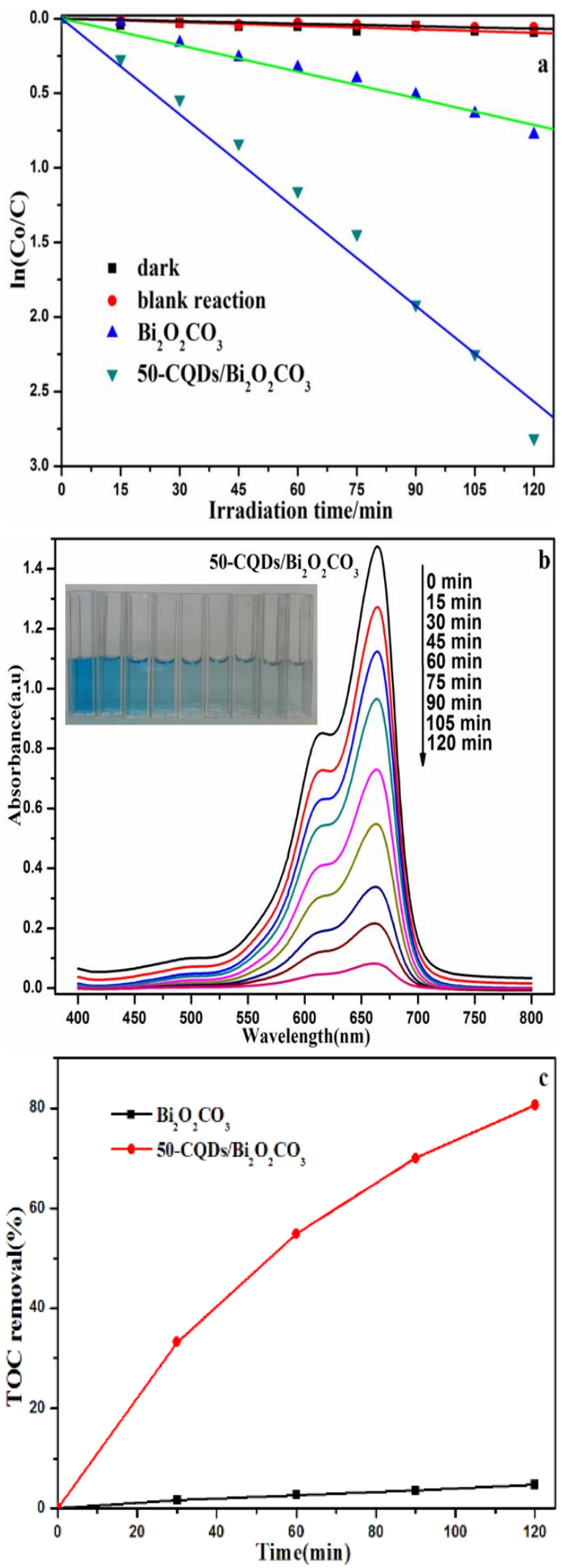

Figure 5. (a) Comparison of the photocatalytic degradation efficiency of MB by different photocatalysts (b) UV-vis spectral absorption changes of $\mathrm{MB}$ solution degraded by the 50-CQDs $/ \mathrm{Bi}_{2} \mathrm{O}_{2} \mathrm{CO}_{3}$ composite; (c) TOC removal of $\mathrm{MB}$. 
In order to verify the role of active species in the organic pollutants degradation process over $\mathrm{CQDs} / \mathrm{Bi}_{2} \mathrm{O}_{2} \mathrm{CO}_{3}$ hybrid materials in detail, quenching experiments were performed. As shown in Figure 6, isopropanol (IPA, $0.01 \mathrm{M}$ ) and ethylenediamine tetraacetic acid disodium (EDTA-2Na, $0.01 \mathrm{M})$ were used to quench the hydroxyl radicals $(\cdot \mathrm{OH})$ and holes $\left(\mathrm{h}^{+}\right)$, Nitrogen $\left(\mathrm{N}_{2}\right)$ was used as the superoxide radical $\left(\cdot \mathrm{O}_{2}^{-}\right)$scavenger. The addition of IPA, EDTA-2Na and $\mathrm{N}_{2}$ made the kinetic constants decrease from $0.0214 \mathrm{~min}^{-1}$ to $0.0086 \mathrm{~min}^{-1}, 0.0033 \mathrm{~min}^{-1}$ and $0.0017 \mathrm{~min}^{-1}$, respectively. As the kinetic constants decreased, a greater effect was observed for the corresponding active species. Therefore, these above results suggested that the $\cdot \mathrm{O}_{2}{ }^{-}, \cdot \mathrm{OH}$ and $\mathrm{h}^{+}$were involved in the photocatalytic degradation process. Moreover, the $\cdot \mathrm{O}_{2}{ }^{-}$was the main active species in degradation process.

To further confirm the generation of $\cdot \mathrm{O}_{2}{ }^{-}$and $\cdot \mathrm{OH}$ species, the ESR spin-trap measurement based on $\mathrm{CQDs} / \mathrm{Bi}_{2} \mathrm{O}_{2} \mathrm{CO}_{3}$ photocatalysts under dark and visible light irradiation was conducted. $\mathrm{DMPO}(5,5$-dimethyl-1-pyrroline $\mathrm{N}$-oxide), a nitrone spin trapping reagent, was utilized to capture the superoxide $\left(\cdot \mathrm{O}_{2}{ }^{-}\right)$and hydroxyl radicals $(\cdot \mathrm{OH})$. As shown in Figure $7 \mathrm{a}, \mathrm{b}$, negligible ESR signals were observed under dark conditions. However, the four-line characteristic ESR signal for DMPO-- $\mathrm{O}_{2}{ }^{-}$, a signal for the DMPO-.OH spin adduct were found under visible light irradiation. Furthermore, in the ESR spectra of DMPO-.OH for CQDs $/ \mathrm{Bi}_{2} \mathrm{O}_{2} \mathrm{CO}_{3}$, four sets of antisymmetric peaks with intensities of 1:2:2:1 were observed, which are the characteristic signals of DMPO-.OH adducts. ESR demonstrates that $\cdot \mathrm{O}_{2}{ }^{-}$and $\cdot \mathrm{OH}$ are the main active species of $\mathrm{CQDs} / \mathrm{Bi}_{2} \mathrm{O}_{2} \mathrm{CO}_{3}$ in the photocatalytic degradation process under visible light illumination.
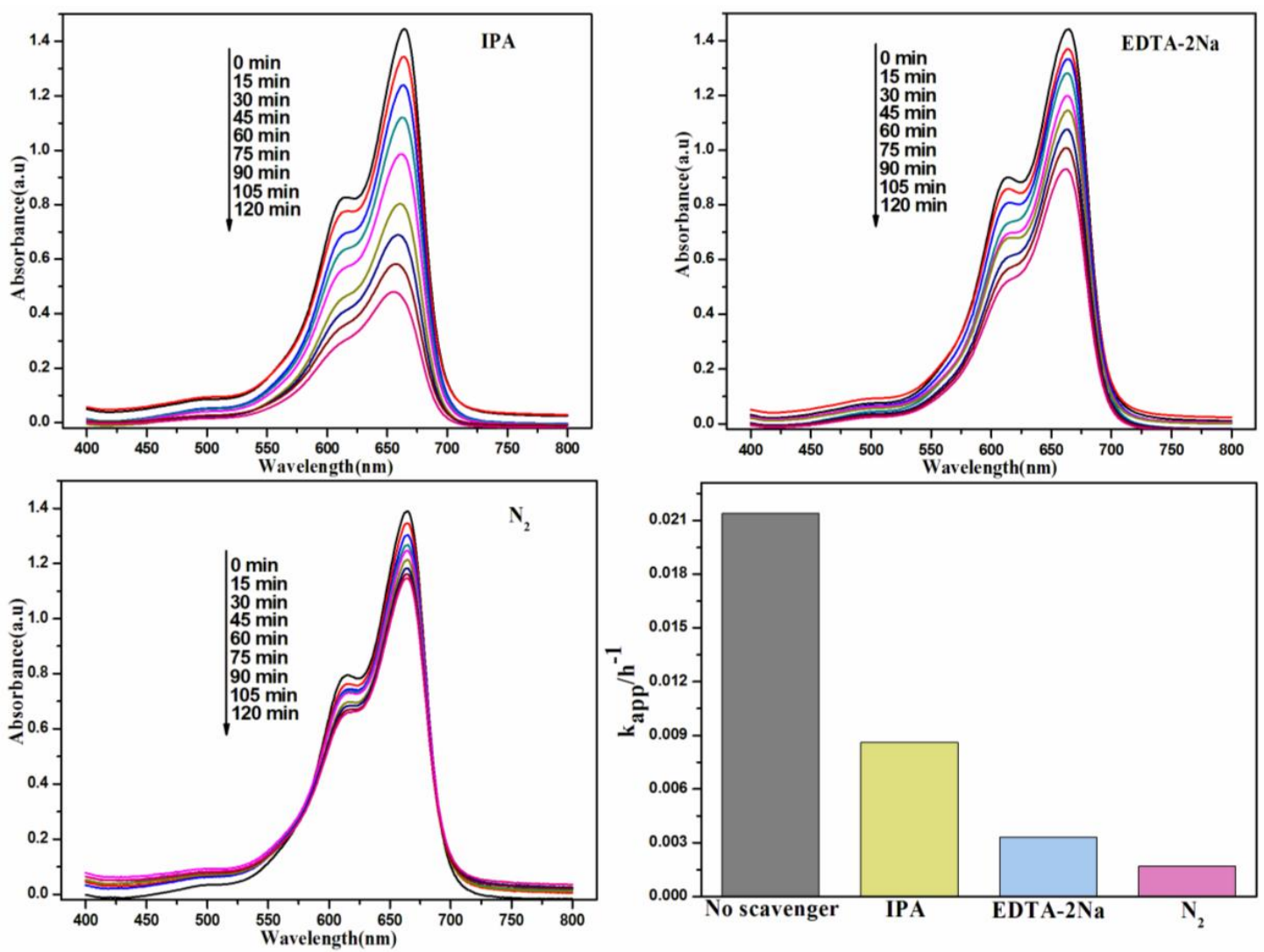

Figure 6. Different photocatalytic degradation performances after adding different quenching agents ((a) IPA, (b)EDTA-2Na, (c) $\mathrm{N}_{2}$ ); (d) The corresponding degradation kinetic constant. 

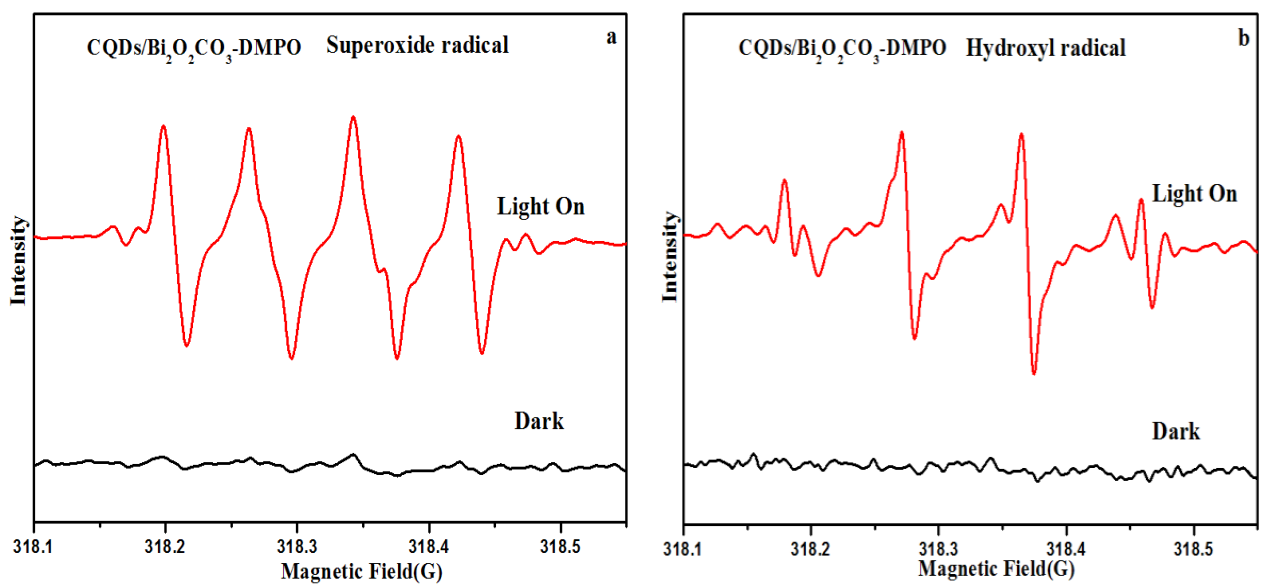

Figure 7. ESR spectra of radical adducts trapped by DMPO: (a) superoxide radical $\left(\cdot \mathrm{O}_{2}{ }^{-}\right)$; (b) hydroxyl radical $(\cdot \mathrm{OH})$.

The stability of the photocatalysts is an important factor in its industrial application. Recycling reactions were used to evaluate the stability of the $\mathrm{CQDs} / \mathrm{Bi}_{2} \mathrm{O}_{2} \mathrm{CO}_{3}$ samples. As shown in Figure 8, the degradation rate of $\mathrm{CQDs} / \mathrm{Bi}_{2} \mathrm{O}_{2} \mathrm{CO}_{3}$ samples decrease from $94.45 \%$ (1st) to $82.91 \%$ (5th); the photocatalytic efficiency was only slightly lower. Considering the loss of catalyst in each cycling process and the test error, the experimental results imply that the $\mathrm{CQDs} / \mathrm{Bi}_{2} \mathrm{O}_{2} \mathrm{CO}_{3}$ possessed good stability. This suggests that the oxygen vacancies of $\mathrm{CQDs} / \mathrm{Bi}_{2} \mathrm{O}_{2} \mathrm{CO}_{3}$ could effectively be refreshed by the up-conversion effect of $\mathrm{CQDs}$, and therefore, $\mathrm{CQDs} / \mathrm{Bi}_{2} \mathrm{O}_{2} \mathrm{CO}_{3}$ possess good stability [55]. $\mathrm{CQDs} / \mathrm{Bi}_{2} \mathrm{O}_{2} \mathrm{CO}_{3}$ materials have great potential and prospects for practical application in the future.

The transient photocurrent response could be used to verify the separation efficiency of photoinduced charges in the samples, as shown in Figure 9. The photocurrent intensity of $\mathrm{Bi}_{2} \mathrm{O}_{2} \mathrm{CO}_{3}$ was $0.04 \mathrm{~mA} / \mathrm{cm}^{2}$. The photocurrent intensity of $\mathrm{CQDs} / \mathrm{Bi}_{2} \mathrm{O}_{2} \mathrm{CO}_{3}$ was higher than that of $\mathrm{Bi}_{2} \mathrm{O}_{2} \mathrm{CO}_{3}$ $\left(0.11 \mathrm{~mA} / \mathrm{cm}^{2}\right)$. The results demonstrated that CQDs in CQDs $/ \mathrm{Bi}_{2} \mathrm{O}_{2} \mathrm{CO}_{3}$ effectively improved the separation of the photogenesis charge, and increased the numbers of generated electrons [55], thus improving the degradation efficiency. These results were consistent with PL analysis (Figure 3); the electrochemical impedance spectra (EIS) (Figure 10) further confirmed this fact.

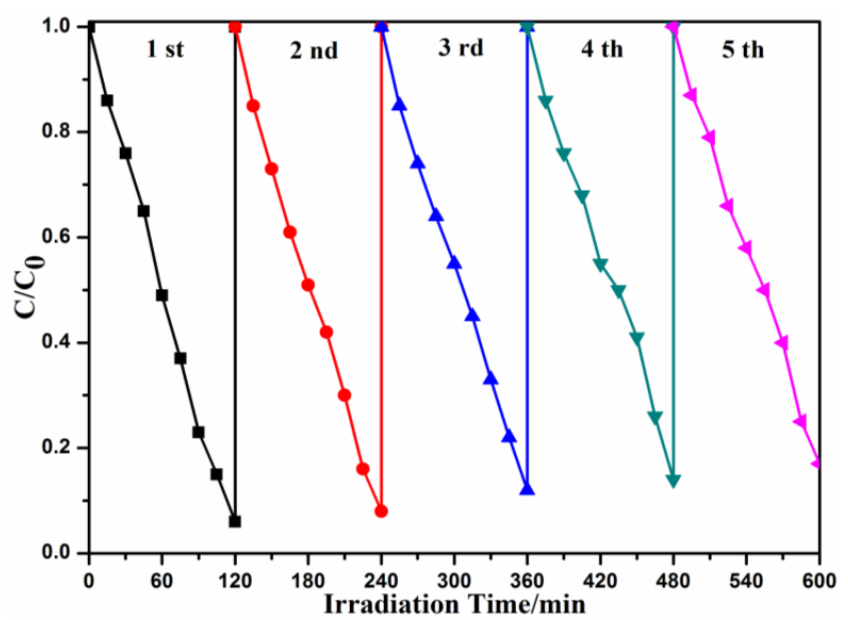

Figure 8. Cycling runs for the photocatalytic degradation of $\mathrm{MB}$ by CQDs $/ \mathrm{Bi}_{2} \mathrm{O}_{2} \mathrm{CO}_{3}$ hybrid materials under visible light irradiation. (MB: $50 \mathrm{~mL}, 10 \mathrm{mg} / \mathrm{L} ; \mathrm{CQDs} / \mathrm{Bi}_{2} \mathrm{O}_{2} \mathrm{CO}_{3}: 1 \mathrm{~g} / \mathrm{L}$ ). 


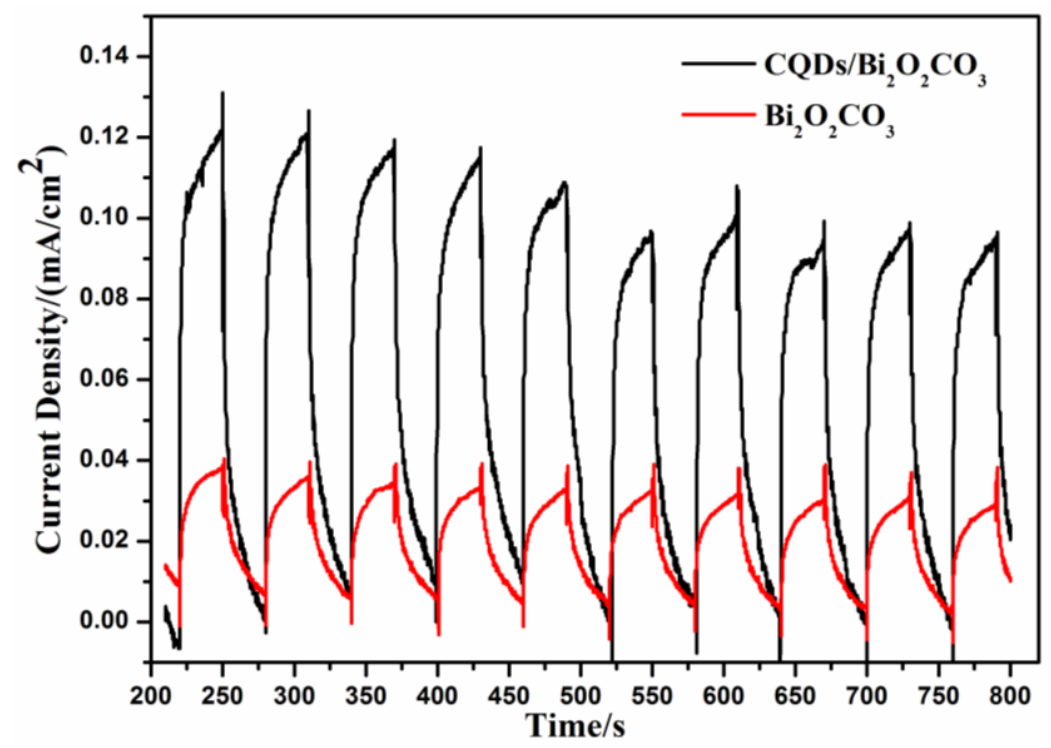

Figure 9. the photocurrent of $\mathrm{Bi}_{2} \mathrm{O}_{2} \mathrm{CO}_{3}$ and $\mathrm{CQDs} / \mathrm{Bi}_{2} \mathrm{O}_{2} \mathrm{CO}_{3}$ under visible light.
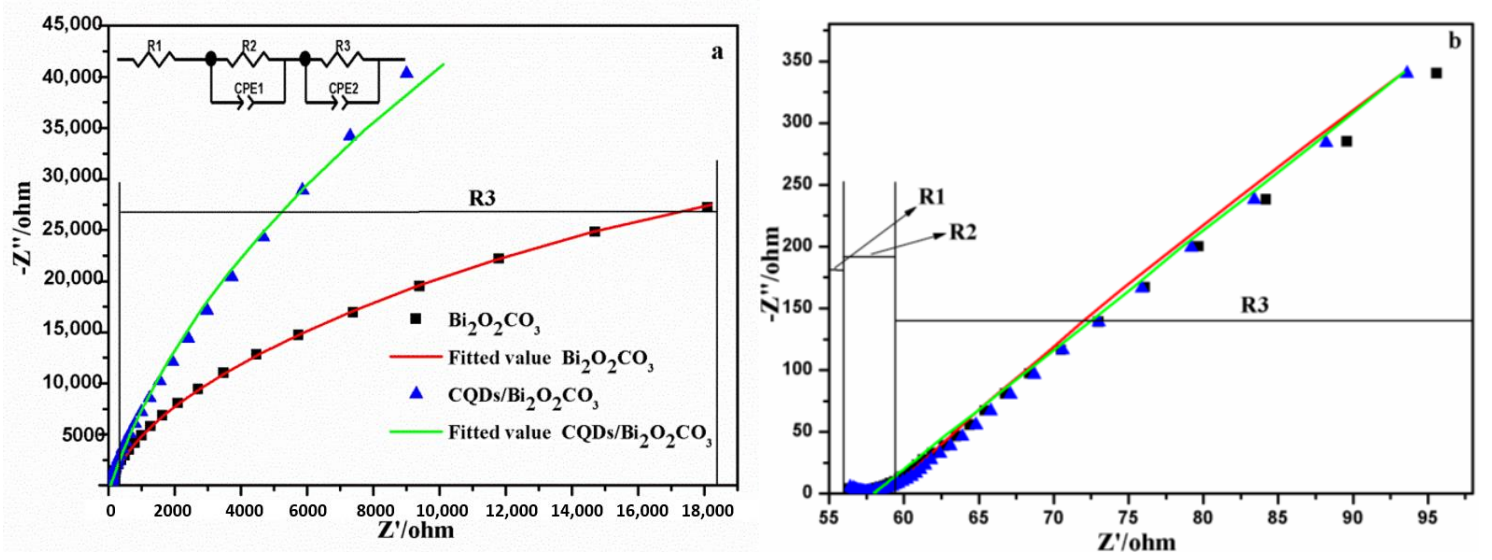

Figure 10. (a) Electrochemical impedance spectra (EIS) of $\mathrm{Bi}_{2} \mathrm{O}_{2} \mathrm{CO}_{3}$ and $\mathrm{CQDs} / \mathrm{Bi}_{2} \mathrm{O}_{2} \mathrm{CO}_{3}$ under visible light; (b) The local amplification of (a).

The most critical drawback in photocatalysis is the recombination process. EIS is quite a useful tool for investigating the charge transfer and recombination processes at the semiconductor/electrolyte interface [56]. Impedance spectra could be fitted by the ZsimpWin software according to the corresponding circuit. As shown in Figure 10a,b, the series resistance (R1) of the Pt counter electrode corresponds to the intercept on the real axis (high frequency). The charge-transfer resistance (R2) of the Pt counter electrode/electrolyte interface corresponds to the first semi-circle (high frequency). The charge-transfer resistance (R3) of the prepared samples anode/electrolyte interface corresponds to the second semi-circle (middle frequency) [57]. Compared with $\mathrm{Bi}_{2} \mathrm{O}_{2} \mathrm{CO}_{3}$, the smaller charge transfer resistance could be obtained from CQDs $/ \mathrm{Bi}_{2} \mathrm{O}_{2} \mathrm{CO}_{3}$ using the smaller arc radius [58]. Thus, the performance of CQDs $/ \mathrm{Bi}_{2} \mathrm{O}_{2} \mathrm{CO}_{3}$ contributed to the fast transfer and effective separation of $\mathrm{e}^{-}-\mathrm{h}^{+}$ pairs. The above results indicated that the introduction of CQDs could improve the electron transfer of photocatalysts and promote the photocatalytic property of CQDs $/ \mathrm{Bi}_{2} \mathrm{O}_{2} \mathrm{CO}_{3}$.

In order to prove the degradation ability of the CQDs $/ \mathrm{Bi}_{2} \mathrm{O}_{2} \mathrm{CO}_{3}$ photocatalyst for organic pollutants, and explore the organic molecule changes in the degradation process, phenol was degraded as the target pollutant under visible light irradiation. Then, this was tested by using high performance liquid chromatography (HPLC). As shown in Figure 11a, the result revealed that the CQDs $/ \mathrm{Bi}_{2} \mathrm{O}_{2} \mathrm{CO}_{3}$ 
sample had a higher photocatalytic property than pure $\mathrm{Bi}_{2} \mathrm{O}_{2} \mathrm{CO}_{3}$ for the phenol; $61.96 \%$ phenol was degraded for $\mathrm{CQDs} / \mathrm{Bi}_{2} \mathrm{O}_{2} \mathrm{CO}_{3}$ within $120 \mathrm{~min}$. As Figure $11 \mathrm{~b}-\mathrm{d}$ shows, the characteristic peak of phenol, located at 3.35 min retention time (RT), gradually weakens with increasing reaction time. No obvious impurity peak appeared in the degradation process. The results imply that phenol degradation was the mineralization process, and that CQDs could effectively promote the photocatalytic property of $\mathrm{CQDs} / \mathrm{Bi}_{2} \mathrm{O}_{2} \mathrm{CO}_{3}$. Additionally, based on the degradation of two types of model organic pollutants (MB and phenol), the above results imply that the $\mathrm{CQDs} / \mathrm{Bi}_{2} \mathrm{O}_{2} \mathrm{CO}_{3}$ has great potential for application in the treatment of organic pollutants.
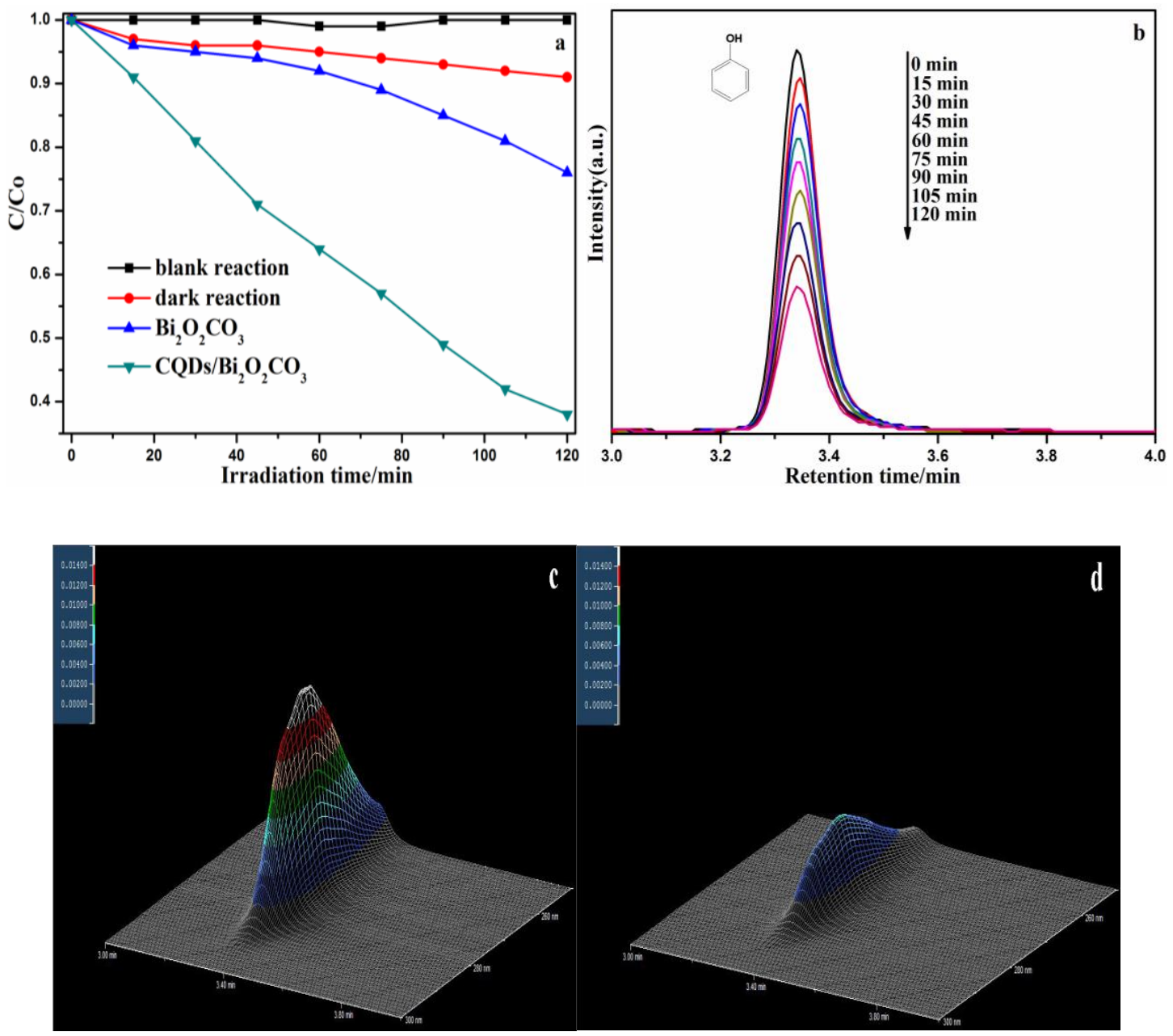

Figure 11. (a) The photocatalytic activity comparison of phenol degradation; (b) HPLC chromatograms of phenol solutions with CQDs $/ \mathrm{Bi}_{2} \mathrm{O}_{2} \mathrm{CO}_{3}$ photocatalyst; (c,d) 3D HPLC spectra of phenol degradation at $0 \mathrm{~min}$ and at $120 \mathrm{~min}$.

According to the characterization and experimental results above, it was found that the CQDs $/ \mathrm{Bi}_{2} \mathrm{O}_{2} \mathrm{CO}_{3}$ exhibited an efficient photocatalytic degradation ability for organic contaminants. The obviously enhanced photocatalytic property of $\mathrm{CQDs} / \mathrm{Bi}_{2} \mathrm{O}_{2} \mathrm{CO}_{3}$ may be attributed to its unique structure. The flower-like $\mathrm{Bi}_{2} \mathrm{O}_{2} \mathrm{CO}_{3}$ functions as a good stabilizer and substrate for CQDs, and the up-conversion effect of CQDs could improve the electron transfer and light absorption ability of photocatalysts and improve $\cdot \mathrm{O}_{2}{ }^{-}$formation. The degradation schematic of $\mathrm{CQDs} / \mathrm{Bi}_{2} \mathrm{O}_{2} \mathrm{CO}_{3}$ is presented in Figure 12. According to the literature and the experimental tests, the energy gap $\left(E_{g}\right)$ of $\mathrm{Bi}_{2} \mathrm{O}_{2} \mathrm{CO}_{3}$ is about $3.4 \mathrm{eV}$, and its valence band (VB) and conduction band (CB) potentials are 3.56 and $0.15 \mathrm{eV}$, respectively. Therefore, there is no obvious photocatalytic activity under visible light irradiation 
for $\mathrm{Bi}_{2} \mathrm{O}_{2} \mathrm{CO}_{3}$. However, CQDs, which possess the up-conversion effect and function as an excellent electron mediator and acceptor in $\mathrm{CQDs} / \mathrm{Bi}_{2} \mathrm{O}_{2} \mathrm{CO}_{3}$, modify the surface of $\mathrm{Bi}_{2} \mathrm{O}_{2} \mathrm{CO}_{3}$, and enhance the visible light response of the photocatalyst due to the electronic coupling between conduction band states of $\mathrm{Bi}_{2} \mathrm{O}_{2} \mathrm{CO}_{3}$ and $\pi$ states of CQDs [38]. As shown in Figure 12, the up-converted PL property of CQDs could take advantage of harnessing the full spectrum of sunlight. This, in turn, excites $\mathrm{Bi}_{2} \mathrm{O}_{2} \mathrm{CO}_{3}$ to form electron-hole pairs, thereby improving photocatalytic activity. $\mathrm{Bi}_{2} \mathrm{O}_{2} \mathrm{CO}_{3}$ could be excited to generate the electron-hole pairs by short wavelength ultraviolet light through up-converting the long wavelength visible light via $\mathrm{CQDs}$ on the surface of $\mathrm{Bi}_{2} \mathrm{O}_{2} \mathrm{CO}_{3}$. When $\mathrm{CQDs} / \mathrm{Bi}_{2} \mathrm{O}_{2} \mathrm{CO}_{3}$ was irradiated by simulated sunlight, the electrons could be excited from the $\mathrm{VB}$ to the $\mathrm{CB}$ of $\mathrm{Bi}_{2} \mathrm{O}_{2} \mathrm{CO}_{3}$, leaving the holes on the $\mathrm{VB}$ of $\mathrm{Bi}_{2} \mathrm{O}_{2} \mathrm{CO}_{3}$. According to the PL spectra, CQDs facilitates the electron transfer from the $\mathrm{CB}$ of $\mathrm{Bi}_{2} \mathrm{O}_{2} \mathrm{CO}_{3}$ to oxygen across $\mathrm{CQDs}$, retarding the recombination [59]. The electrons could then reduce the adsorbed $\mathrm{O}_{2}$ to $\cdot \mathrm{O}_{2}{ }^{-}$. Meanwhile the $\mathrm{h}^{+}$on the $\mathrm{VB}$ of $\mathrm{Bi}_{2} \mathrm{O}_{2} \mathrm{CO}_{3}$ could react with the $\mathrm{OH}^{-}$and/or $\mathrm{H}_{2} \mathrm{O}$ to produce $\cdot \mathrm{OH}$, or a portion of the holes could also oxidize the organic pollutant directly [60]. The generated reactive oxygen species played an important role in the photocatalytic degradation process. These effects would guarantee the high photocatalytic activities of the CQDs modified $\mathrm{Bi}_{2} \mathrm{O}_{2} \mathrm{CO}_{3}$ samples.

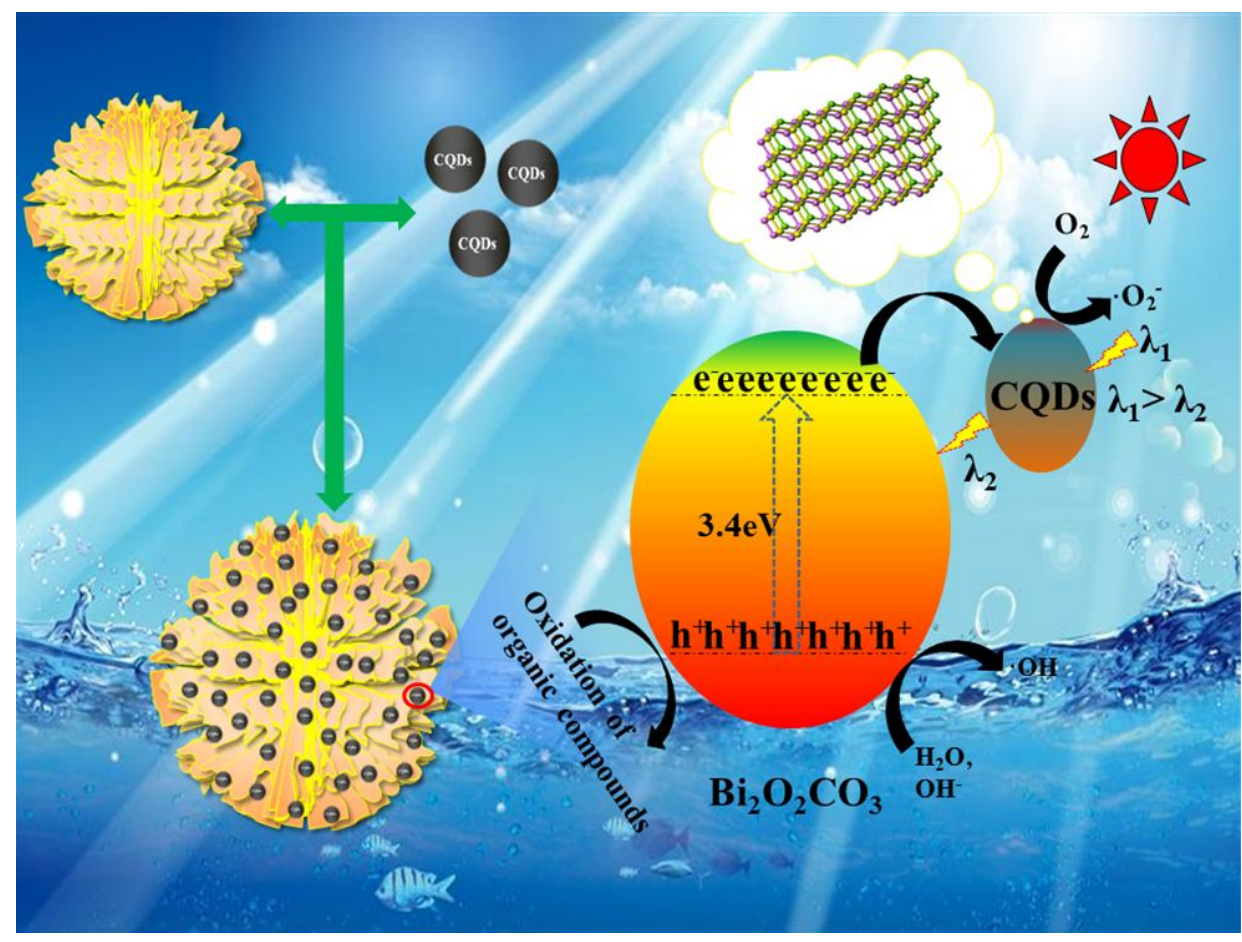

Figure 12. Schematic of the possible reaction mechanism for organic pollutants degradation by $\mathrm{CQDs} / \mathrm{Bi}_{2} \mathrm{O}_{2} \mathrm{CO}_{3}$ under the simulated sunlight irradiation.

\section{Conclusions}

In summary, $\mathrm{CQDs}$ modified $\mathrm{Bi}_{2} \mathrm{O}_{2} \mathrm{CO}_{3}\left(\mathrm{CQDs} / \mathrm{Bi}_{2} \mathrm{O}_{2} \mathrm{CO}_{3}\right)$ was prepared by a simple dynamic adsorption precipitation method at room temperature. With CQDs approximately 2-5 nm in size evenly dispersed on the surface of $\mathrm{Bi}_{2} \mathrm{O}_{2} \mathrm{CO}_{3}, \mathrm{CQDs} / \mathrm{Bi}_{2} \mathrm{O}_{2} \mathrm{CO}_{3}$ has efficient photocatalytic activity and long term stability under visible light. The photocatalytic degradation efficiency of methylene blue and phenol rate can reach up to $94.45 \%$ and $61.46 \%$ within $2 \mathrm{~h}$, respectively. Photoelectrochemical testing proved that the introduction of CQDs (as electron acceptors) effectively suppresses the recombination of $\mathrm{e}^{-}-\mathrm{h}^{+}$and promotes charge transfer. The quenching results suggested that $\cdot \mathrm{O}_{2}{ }^{-}, \mathrm{h}^{+}$and $\cdot \mathrm{OH}$ were involved in the photocatalytic degradation process. These results demonstrated that the excellent photocatalytic performance for $\mathrm{CQDs} / \mathrm{Bi}_{2} \mathrm{O}_{2} \mathrm{CO}_{3}$ can be attributed to the up-conversion effect of 
CQDs. The up-conversion effect of CQDs could improve $\cdot \mathrm{O}_{2}{ }^{-}$formation and the electron transfer and light absorption ability of photocatalysts. Furthermore, the up-conversion effect of CQDs could help maintain photocatalytic stability. The above results can provide important inspiration for the development of other CQDs-based photocatalytic materials.

Supplementary Materials: The following are available online at http:/ /www.mdpi.com/2079-4991/8/5/330/s1, Figure S1: (a) UV-vis diffuse reflectance spectrum (DRS) and (b) the band gap energies (Eg) of $\mathrm{Bi}_{2} \mathrm{O}_{2} \mathrm{CO}_{3}$ and different $\mathrm{CQDs} / \mathrm{Bi}_{2} \mathrm{O}_{2} \mathrm{CO}_{3}$ samples, Figure S2: (a) Valence band X-ray photoelectron spectroscopy (VB XPS) spectrum of $\mathrm{Bi}_{2} \mathrm{O}_{2} \mathrm{CO}_{3}$. (b) Mott-Schottky (MS) plots of $\mathrm{Bi}_{2} \mathrm{O}_{2} \mathrm{CO}_{3}$ photoelectrode, Figure S3: FTIR spectra of CQDs, $\mathrm{Bi}_{2} \mathrm{O}_{2} \mathrm{CO}_{3}$ and $\mathrm{CQDs} / \mathrm{Bi}_{2} \mathrm{O}_{2} \mathrm{CO}_{3}$ samples, Figure S4: kinetic constant for the degradation of $\mathrm{MB}$ with the $\mathrm{CQDs} / \mathrm{Bi}_{2} \mathrm{O}_{2} \mathrm{CO}_{3}$ composites prepared with different amounts of CQDs.

Author Contributions: S.L. and Z.Z. conceived and designed the experiments; S.L. and T.Z. performed the experiments; S.L. and H.L. analyzed the data; X.L. and W.C. contributed reagents/materials/analysis tools; S.L. wrote the paper.

Funding: This work was funded by the National Natural Science Foundation of China (grant No. 21476161), the Hebei Provincial Foundation for International Cooperation (No. 15391403D) and the Natural Sciences and Engineering Research Council of Canada (Discovery). Z.Z. and S.L. both contributed equally to this work.

Conflicts of Interest: The authors declare no conflict of interest.

\section{References}

1. Que, Q.H.; Xing, Y.L.; He, Z.L.; Yang, Y.W.; Yin, X.T.; Que, W.X. $\mathrm{Bi}_{2} \mathrm{O}_{3} /$ Carbon quantum dots heterostructured photocatalysts with enhanced photocatalytic activity. Mater. Lett. 2017, 209, 220-223. [CrossRef]

2. Kian, M.L.; Chin, W.L.; Koh, S.N.; Joon, C.J. Recent developments of zinc oxide based photocatalyst in water treatment technology: A review. Water Res. 2016, 88, 428-448.

3. Yogendra, K.M.; Rainer, A. ZnO tetrapod materials for functional applications. Mater. Today 2018. [CrossRef]

4. Wang, H.L.; Zhang, L.S.; Chen, Z.G.; Hu, J.Q.; Li, S.J.; Wang, Z.H.; Liu, J.S.; Wang, X.C. Semiconductor heterojunction photocatalysts: Design, construction, and photocatalytic performances. Chem. Soc. Rev. 2014, 43, 5234-5244. [CrossRef] [PubMed]

5. Zhao, Z.M.; Sun, J.; Xing, S.M.; Liu, D.J.; Zhang, G.J.; Bai, L.J.; Jiang, B.L. Enhanced Raman scattering and photocatalytic activity of $\mathrm{TiO}_{2}$ films with embedded $\mathrm{Ag}$ nanoparticles deposited by magnetron sputtering. J. Alloys Compd. 2016, 679, 88-93. [CrossRef]

6. Guo, Q.; Zhou, C.Y.; Ma, Z.B.; Ren, Z.F.; Fan, H.J.; Yang, X.M. Elementary photocatalytic chemistry on $\mathrm{TiO}_{2}$ surfaces. Chem. Soc. Rev. 2016, 45, 3701-3730. [CrossRef] [PubMed]

7. Zheng, L.X.; Han, S.C.; Liu, H.; Yu, P.P.; Fang, X.S. Hierarchical $\mathrm{MoS}_{2}$ nanosheet@TiO $\mathrm{O}_{2}$ nanotube array composites with enhanced photocatalytic and photocurrent performances. Small 2016, 12, 1527-1536. [CrossRef] [PubMed]

8. Liu, C.; Han, R.R.; Ji, H.M.; Sun, T.; Zhao, J.; Chen, N.N.; Chen, J.; Guo, X.F.; Hou, W.H.; Ding, W.P. S-doped mesoporous nanocomposite of $\mathrm{HTiNbO}_{5}$ nanosheets and $\mathrm{TiO}_{2}$ nanoparticles with enhanced visible light photocatalytic activity. Phys. Chem. Chem. Phys. 2016, 18, 801-810. [CrossRef] [PubMed]

9. Xie, T.P.; Xu, L.J.; Liu, C.L.; Wang, Y. Magnetic composite $\mathrm{ZnFe}_{2} \mathrm{O}_{4} / \mathrm{SrFe}_{12} \mathrm{O}_{19}$ : Preparation, characterization, and photocatalytic activity under visible light. Appl. Surf. Sci. 2013, 273, 684-691. [CrossRef]

10. García-Pérez, U.M.; Sepúlveda-Guzmán, S.; Martínezde la Cruz, A. Nanostructured $\mathrm{BiVO}_{4}$ photocatalysts synthesized via a polymer-assisted coprecipitation method and their photocatalytic properties under visible-light irradiation. Solid State Sci. 2012, 14, 293-298. [CrossRef]

11. Zhu, Z.F.; Zhang, L.; Li, J.Q.; Du, J.; Zhang, Y.B.; Zhou, J.Q. Synthesis and photocatalytic behavior of $\mathrm{BiVO}_{4}$ with decahedral structure. Ceram. Int. 2013, 39, 7461-7465. [CrossRef]

12. Dong, S.Y.; Feng, J.L.; Li, Y.K.; Hu, L.M.; Liu, M.L.; Wang, Y.F.; Pi, Y.Q.; Sun, J.Y.; Sun, J.H. Shape-controlled synthesis of $\mathrm{BiVO}_{4}$ hierarchical structures with unique natural-sunlight-driven photocatalytic activity. Appl. Catal. B 2014, 152-153, 413-424. [CrossRef]

13. Zhuo, Y.Q.; Huang, J.F.; Cao, L.Y.; Ouyang, H.B.; Wu, J.P. Photocatalytic activity of snow-like $\mathrm{Bi}_{2} \mathrm{WO}_{6}$ microcrystalline for decomposition of Rhodamine B under natural sunlight irradiation. Mater. Lett. 2013, 90, 107-110. [CrossRef] 
14. Dumrongrojthanath, P.; Thongtem, T.; Phuruangrat, A.; Thongtem, S. Hydrothermal synthesis of $\mathrm{Bi}_{2} \mathrm{WO}_{6}$ hierarchical flowers with their photonic and photocatalytic properties. Superlattices Microstruct. 2013, 54, 71-77. [CrossRef]

15. Zhang, L.S.; Wang, H.L.; Chen, Z.G.; Wong, P.K.; Liu, J.S. $\mathrm{Bi}_{2} \mathrm{WO}_{6}$ micro/nanostructures: Synthesis modifications and visible-light-driven photocatalytic applications. Appl. Catal. B 2011, 106, 1-13.

16. Hu, J.L.; Fan, W.J.; Ye, W.Q.; Huang, C.J.; Qiu, X.Q. Insights into the photosensitivity activity of BiOCl under visible light irradiation. Appl. Catal. B 2014, 158-159, 182-189. [CrossRef]

17. Chai, B.; Zhou, H.; Zhang, F.; Liao, X.; Ren, M.X. Visible light photocatalytic performance of hierarchical BiOBr microspheres synthesized via a reactable ionic liquid. Mater. Sci. Semicond. Process. 2014, 23, 151-158. [CrossRef]

18. Li, T.T.; Luo, S.L.; Yang, L.X. Three-dimensional hierarchical Ag/AgI/BiOI microspheres with high visible-light photocatalytic activity. Mater. Lett. 2013, 109, 247-252. [CrossRef]

19. Zhang, Q.Y.; Tian, H.; Li, N.; Chen, M.D.; Teng, F. Controllable growth of novel $\mathrm{BiPO}_{4}$ dendrites by an innovative approach and high energy facets-dependent photocatalytic activity. CrystEngComm 2014, 16, 8334-8339. [CrossRef]

20. Lin, X.; Liu, D.; Guo, X.Y.; Sun, N.; Zhao, S.; Chang, L.M.; Zhai, H.J.; Wang, Q.W. Fabrication and efficient visible light-induced photocatalytic activity of $\mathrm{Bi}_{2} \mathrm{MoO}_{6} / \mathrm{BiPO}_{4}$ composite. J Phys. Chem. Solids 2015, 76, 170-176. [CrossRef]

21. Huang, Y.; Wang, W.; Zhang, Q.; Cao, J.J.; Huang, R.J.; Ho, W.K.; Lee, S.C. In situ fabrication of a- $\mathrm{Bi}_{2} \mathrm{O}_{3} / \mathrm{BiO}_{2} \mathrm{CO}_{3}$ nanoplate heterojunctions with tunable optical property and photocatalytic activity. Sci. Rep. 2016, 6, 23435. [CrossRef] [PubMed]

22. Zheng, Y.; Duan, F.; Chen, M.Q.; Xie, Y. Synthetic $\mathrm{Bi}_{2} \mathrm{O}_{2} \mathrm{CO}_{3}$ nanostructures: Novel photocatalyst with controlled special surface exposed. J. Mol. Catal. A Chem. 2010, 317, 34-40. [CrossRef]

23. Yang, L.L.; Han, Q.F.; Zhu, J.W.; Wang, X. Synthesis of egg-tart shaped $\mathrm{Bi}_{2} \mathrm{O}_{2} \mathrm{CO}_{3}$ hierarchical nanostructures from single precursor and its photocatalytic performance. Mater. Lett. 2015, 138, 235-237. [CrossRef]

24. Cai, G.Y.; Xu, L.L.; Wei, B.; Che, J.X.; Gao, H.; Sun, W.J. Facile synthesis of $\beta-\mathrm{Bi}_{2} \mathrm{O}_{3} / \mathrm{Bi}_{2} \mathrm{O}_{2} \mathrm{CO}_{3}$ nanocomposite with high visible-light photocatalytic activity. Mater. Lett. 2014, 120, 1-4. [CrossRef]

25. Chen, L.; Yin, S.F.; Luo, S.L.; Huang, R.; Zhang, Q.; Hong, T.; Au, P.C.T. $\mathrm{Bi}_{2} \mathrm{O}_{2} \mathrm{CO}_{3} / \mathrm{BiOI}$ Photocatalysts with Heterojunctions Highly Efficient for Visible-Light Treatment of Dye-Containing Wastewater. Ind. Eng. Chem. Res. 2012, 51, 6760-6768. [CrossRef]

26. Jin, L.; Zhu, G.Q.; Hojamberdiev, M.; Luo, X.C.; Tan, C.W.; Peng, J.H.; Wei, X.M.; Li, J.P.; Liu, P. A plasmonic $\mathrm{AgAgBr} / \mathrm{Bi}_{2} \mathrm{O}_{2} \mathrm{CO}_{3}$ composite photocatalyst with enhanced visible-light photocatalytic activity. Ind. Eng. Chem. Res. 2014, 53, 13718-13727. [CrossRef]

27. Wang, W.J.; Cheng, H.F.; Huang, B.B.; Lin, X.J.; Qin, X.Y.; Zhang, X.Y.; Dai, Y. Synthesis of $\mathrm{Bi}_{2} \mathrm{O}_{2} \mathrm{CO}_{3} / \mathrm{Bi}_{2} \mathrm{~S}_{3}$ hierarchical microspheres with heterojunctions and their enhanced visible light-driven photocatalytic degradation of dye pollutants. J Colloid. Interface Sci. 2013, 402, 34-39. [CrossRef] [PubMed]

28. Baker, S.N.; Baker, G.A. Luminescent Carbon Nanodots: Emergent Nanolights. Angew. Chem. Int. Ed. 2010, 49, 6726-6744. [CrossRef] [PubMed]

29. Shen, J.H.; Zhu, Y.H.; Yang, X.L.; Li, C.Z. Graphene quantum dots: Emergent nanolights for bioimaging, sensors, catalysis and photovoltaic devices. Chem. Commun. 2012, 48, 3686-3699. [CrossRef] [PubMed]

30. Li, H.T.; Kang, Z.H.; Liu, Y.; Lee, S.T. Carbon nanodots: Synthesis, properties and applications. J. Mater. Chem. 2012, 22, 24230-24253. [CrossRef]

31. Tang, D.; Zhang, H.; Huang, H.; Liu, R.; Han, Y.; Liu, Y.; Tong, C.; Kang, Z.H. Carbon quantum dots enhance the photocatalytic performance of BiVO4 with different exposed facets. Dalton Trans. 2013, 42, 6285-6289. [CrossRef] [PubMed]

32. Li, H.; He, X.; Kang, Z.; Huang, H.; Liu, Y.; Liu, J.; Lian, S.; Tsang, C.; Yang, X.; Lee, S.T. Water-Soluble Fluorescent Carbon Quantum Dots and Photocatalyst Design. Angew. Chem. Int. Ed. 2010, 49, 4430-4434. [CrossRef] [PubMed]

33. Gupta, V.; Chaudhary, N.; Srivastava, R.; Sharma, G.D.; Bhardwaj, R.; Chand, S. Luminscent Graphene Quantum Dots for Organic Photovoltaic Devices. J. Am. Chem. Soc. 2011, 133, 9960-9963. [CrossRef] [PubMed] 
34. Zhu, S.; Meng, Q.; Wang, L.; Zhang, J.; Song, Y.; Jin, H.; Zhang, K.; Sun, H.; Wang, H.; Yang, B. Highly Photoluminescent Carbon Dots for Multicolor Patterning, Sensors, and Bioimaging. Angew. Chem. Int. Ed. 2013, 52, 3953-3957. [CrossRef] [PubMed]

35. Li, H.T.; Liu, R.H.; Lian, S.Y.; Liu, Y.; Huang, H.; Kang, Z.H. Near-infrared light controlled photocatalytic activity of carbon quantum dots for highly selective oxidation reaction. Nanoscale 2013, 5, 3289-3297. [CrossRef] [PubMed]

36. Zhang, H.C.; Ming, H.; Lian, S.Y.; Huang, H.; Li, H.T.; Zhang, L.L.; Liu, Y.; Kang, Z.H.; Lee, S.T. Fe ${ }_{2} \mathrm{O}_{3} /$ carbon quantum dots complex photocatalysts and their enhanced photocatalytic activity under visible light. Dalton Trans. 2011, 40, 10822-10825. [CrossRef] [PubMed]

37. Yu, H.; Zhang, H.C.; Huang, H.; Liu, Y.; Li, H.T.; Ming, H.; Kang, Z.H. ZnO/carbon quantum dots nanocomposites: One-step fabrication and superior photocatalytic ability for toxic gas degradation under visible light at room temperature. New J. Chem. 2012, 36, 1031-1035. [CrossRef]

38. Ming, H.; Ma, Z.; Liu, Y.; Pan, K.M.; Yu, H.; Wang, F.; Kang, Z.H. Large scale electrochemical synthesis of high quality carbon nanodots and their photocatalytic property. Dalton Trans. 2012, 41, 9526-9531. [CrossRef] [PubMed]

39. Tian, N.; Huang, H.W.; Guo, Y.X.; He, Y.; Zhang, Y.H. A g- $\mathrm{C}_{3} \mathrm{~N}_{4} / \mathrm{Bi}_{2} \mathrm{O}_{2} \mathrm{CO}_{3}$ composite with high visible-light-driven photocatalytic activity for rhodamine B degradation. Appl. Surf. Sci. 2014, 322, 249-254. [CrossRef]

40. Huang, H.W.; Wang, S.B.; Tian, N.; Hang, Y.H. One-step hydrothermal preparation strategy for layered $\mathrm{BiIO}_{4} / \mathrm{Bi}_{2} \mathrm{WO}_{6}$ heterojunctions with enhanced visible light photocatalytic activities. RSC Adv. 2014, 4, 5561-5567. [CrossRef]

41. Huang, H.W.; Li, X.W.; Wang, J.J.; Dong, F.; Chu, P.K.; Zhang, T.R.; Zhang, Y.H. Anionic Group Self-Doping as a Promising Strategy: Band-Gap Engineering and Multi-Functional Applications of High-Performance $\mathrm{CO}_{3}{ }^{2-}$-Doped $\mathrm{Bi}_{2} \mathrm{O}_{2} \mathrm{CO}_{3}$. ACS Catal. 2015, 5, 4094-4103. [CrossRef]

42. Huang, H.W.; Yao, J.Y.; Lin, Z.S.; Wang, X.Y.; He, R.; Yao, W.J.; Zhai, N.X.; Chen, C.T. $\mathrm{NaSr}_{3} \mathrm{Be}_{3} \mathrm{~B}_{3} \mathrm{O}_{9} \mathrm{~F}_{4}$ : A promising deep-ultraviolet nonlinear optical material resulting from the cooperative alignment of the $\left[\mathrm{Be}_{3} \mathrm{~B}_{3} \mathrm{O}_{12} \mathrm{~F}_{10}{ }^{-}\right.$anionic group. Angew. Chem. Int. Ed. 2011, 50, 9141-9144. [CrossRef] [PubMed]

43. Wang, H.; Liang, Y.H.; Liu, L.; Hu, J.S.; Cui, W.Q. Reduced graphene oxide wrapped $\mathrm{Bi}_{2} \mathrm{WO}_{6}$ hybrid with ultrafast charge separation and improved photoelectrocatalytic performance. Appl. Surf. Sci. 2017, 392, 51-60. [CrossRef]

44. Yu, J.C.; Yu, J.G.; Ho, W.K.; Jiang, Z.T.; Zhang, L.Z. Effects of F-doping on the photocatalytic activity and microstructures of nanocrystalline $\mathrm{TiO}_{2}$ powders. Chem. Mater. 2002, 14, 3808-3816. [CrossRef]

45. Tobon-Zapata, G.E.; Etcheverry, S.B.; Baran, E.J. Vibrational spectrum of bismuth subcarbonate. J. Mater. Sci. Lett. 1997, 16, 656-657. [CrossRef]

46. Li, J.Z.; Wang, N.Y.; Tran, T.T.; Huang, C.A.; Chen, L.; Yuan, L.J.; Zhou, L.P.; Shen, R.; Cai, Q.Y. Electrogenerated chemiluminescence detection of trace level pentachlorophenol using carbon quantum dots. Analyst 2013, 138, 2038-2043. [CrossRef] [PubMed]

47. Kaur, S.; Sharma, S.; Kansal, S.K. Synthesis of ZnS/CQDs nanocomposite and its application as a photocatalyst for the degradation of an anionic dye. Superlattice Microstruct. 2016, 98, 86-95. [CrossRef]

48. Zhang, P.; Shao, C.L.; Zhang, M.Y.; Guo, Z.C.; Mu, J.B.; Zhang, Z.Y.; Zhang, X.; Liu, Y.C. Bii ${ }_{2} \mathrm{MoO}_{6}$ ultrathin nanosheets on $\mathrm{ZnTiO}_{3}$ nanofibers: A 3D open hierarchical heterostructures synergistic system with enhanced visible-light-driven photocatalytic activity. J. Hazard. Mater. 2012, 217-218, 422-428. [CrossRef] [PubMed]

49. Qian, X.F.; Yue, D.T.; Tian, Z.Y.; Reng, M.; Zhu, Y.; Kan, M.; Zhang, T.Y.; Zhao, Y.X. Carbon quantum dots decorated $\mathrm{Bi}_{2} \mathrm{WO}_{6}$ nanocomposite with enhanced photocatalytic oxidation activity for VOCs. Appl. Catal. B 2016, 193, 16-21. [CrossRef]

50. Yu, B.Y.; Kwak, S.Y. Carbon quantum dots embedded with mesoporous hematite nanospheres as efficient visible light-active photocatalysts. J. Mater. Chem. 2012, 22, 8345-8353. [CrossRef]

51. Liu, Y.; Yu, S.; Zhao, Z.Y.; Dong, F.; Dong, X.A.; Zhou, Y. N-Doped $\mathrm{Bi}_{2} \mathrm{O}_{2} \mathrm{CO}_{3}$ /Graphene Quantum Dot Composite Photocatalyst: Enhanced Visible-Light Photocatalytic NO Oxidation and In Situ DRIFTS Studies. J. Phys. Chem. C 2017, 121, 12168-12177. [CrossRef]

52. Yu, X.J.; Liu, J.J.; Yu, Y.C.; Zuo, S.L.; Li, B.S. Preparation and visible light photocatalytic activity of carbon quantum dots $/ \mathrm{TiO}_{2}$ nanosheet composites. Carbon 2014, 68, 718-724. [CrossRef] 
53. Donat, F.; Corbel, S.; Alem, H.; Pontvianne, S.; Balan, L.; Medjahdi, G.; Schneider, R. ZnO nanoparticles sensitized by CuInZn $\mathrm{n}_{x} \mathrm{~S}_{2+x}$ quantum dots as highly efficient solar light driven photocatalysts. Beilstein J. Nanotechnol. 2017, 8, 1080-1093. [CrossRef] [PubMed]

54. Candal, R.J.; Zeltner, W.A.; Anderson, M.A. Effects of $\mathrm{pH}$ and Applied Potential on Photocurrent and Oxidation Rate of Saline Solutions of Formic Acid in a Photoelectrocatalytic Reactor. Environ. Sci. Technol. 2000, 34, 3443-3451. [CrossRef]

55. Duo, F.F.; Wang, Y.W.; Fan, C.M.; Zhang, X.C.; Wang, Y.F. Enhanced visible light photocatalytic activity and stability of CQDs/BiOBr composites: The upconversion effect of CQDs. J Alloys Compd. 2016, 685, 34-41. [CrossRef]

56. Hasan, M.R.; Hamid, S.B.A.; Basirun, W.J.; Chowdhury, Z.Z.; Kandjani, A.E.; Bhargava, S.K. Ga doped RGO- $\mathrm{TiO}_{2}$ composite on an ITO surface electrode for investigation of photoelectrocatalytic activity under visible light irradiation. New J. Chem. 2015, 39, 369-376. [CrossRef]

57. Liang, Y.H.; Lin, S.L.; Liu, L.; Hu, J.S.; Cui, W.Q. Oil-in-water self-assembled Ag@AgCl QDs sensitized $\mathrm{Bi}_{2} \mathrm{WO}_{6}$ : Enhanced photocatalytic degradation under visible light irradiation. Appl. Catal. B 2015, 164, 192-203. [CrossRef]

58. Cong, Y.Q.; Ji, Y.; Ge, Y.H.; Jin, H.; Zhang, Y.; Wang, Q. Fabrication of $3 \mathrm{D} \mathrm{Bi}_{2} \mathrm{O}_{3}$-BiOI heterojunction by a simple dipping method: Highly enhanced visible-light photoelectrocatalytic activity. Chem. Eng. J. 2017, 307, 572-582. [CrossRef]

59. Fang, S.; Xia, Y.; Lv, K.L.; Li, Q.; Sun, J.; Li, M. Effect of carbon-dots modification on the structure and

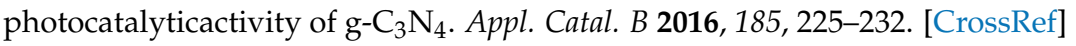

60. Hu, C.; Lan, Y.Q.; Qu, J.H.; Hu, X.X.; Wang, A.M. Ag/AgBr $/ \mathrm{TiO}_{2}$ Visible Light Photocatalyst for Destruction of Azodyes and Bacteria. J. Phys. Chem. B 2006, 110, 4066-4072. [CrossRef] [PubMed]

(C) 2018 by the authors. Licensee MDPI, Basel, Switzerland. This article is an open access article distributed under the terms and conditions of the Creative Commons Attribution (CC BY) license (http:/ / creativecommons.org/licenses/by/4.0/). 